\title{
A comparison of the present and last interglacial periods in six Antarctic ice cores
}

\author{
V. Masson-Delmotte ${ }^{1}$, D. Buiron ${ }^{2}$, A. Ekaykin ${ }^{3}$, M. Frezzotti ${ }^{4}$, H. Gallée ${ }^{2}$, J. Jouzel ${ }^{1}$, G. Krinner ${ }^{2}$, A. Landais ${ }^{1}$, \\ H. Motoyama ${ }^{5}$, H. Oerter ${ }^{6}$, K. Pol ${ }^{1}$, D. Pollard ${ }^{7}$, C. Ritz ${ }^{2}$, E. Schlosser ${ }^{8}$, L. C. Sime ${ }^{9}$, H. Sodemann ${ }^{10}$, B. Stenni ${ }^{11}$, \\ R. Uemura ${ }^{1,12}$, and F. Vimeux ${ }^{1,13}$ \\ ${ }^{1}$ Laboratoire des Sciences du Climat et de l'Environnemen, IPSL-CEA-CNRS-UVSQ, UMR 8212, Gif-sur-Yvette, France \\ ${ }^{2}$ CNRS and UJF, Laboratoire de Glaciologie et Géophysique de l'Environnement (LGGE, UMR 5183), Grenoble, France \\ ${ }^{3}$ Arctic and Antarctic Research Institute, 38 Beringa St., 199397 St. Petersburg, Russia \\ ${ }^{4}$ ENEA, Rome, Italy \\ ${ }^{5}$ Research Organization of Information and Systems, National Institute of Polar Research, 10-3, Midoricho, Tachikawa, \\ Tokyo, 190-8518, Japan \\ ${ }^{6}$ Alfred Wegener Institute for Polar and Marine Research, Helmholtz Association, Bremerhaven, Germany \\ ${ }^{7}$ Earth and Environmental System Institute, Pennsylvania State University, University Park, USA \\ ${ }^{8}$ Institute of Meteorology and Geophysics, University of Innsbruck, Innsbruck, Austria \\ ${ }^{9}$ British Antarctic Survey, Cambridge, UK \\ ${ }^{10}$ Norwegian Institute for Air Research, NILU, Kjeller, Norway \\ ${ }^{11}$ Department of Geosciences, University of Trieste, Trieste, Italy \\ ${ }^{12}$ Department of Chemistry, Biology and Marine Science, University of the Ryukyus, Nishihara, Okinawa, Japan \\ ${ }^{13}$ Institut de Recherche pour le Développement, IRD, Laboratoire HydroSciences Montpellier, HSM, UMR 5569, \\ CNRS-IRD-UM1-UM2, Montpellier, France
}

Received: 27 September 2010 - Published in Clim. Past Discuss.: 26 October 2010

Revised: 2 March 2011 - Accepted: 10 March 2011 - Published: 28 April 2011

\begin{abstract}
We compare the present and last interglacial periods as recorded in Antarctic water stable isotope records now available at various temporal resolutions from six East Antarctic ice cores: Vostok, Taylor Dome, EPICA Dome C (EDC), EPICA Dronning Maud Land (EDML), Dome Fuji and the recent TALDICE ice core from Talos Dome. We first review the different modern site characteristics in terms of ice flow, meteorological conditions, precipitation intermittency and moisture origin, as depicted by meteorological data, atmospheric reanalyses and Lagrangian moisture source diagnostics. These different factors can indeed alter the relationships between temperature and water stable isotopes. Using five records with sufficient resolution on the EDC3 age scale, common features are quantified through principal component analyses. Consistent with instrumental records and atmospheric model results, the ice core data depict rather coherent and homogenous patterns in East Antarctica during the last two interglacials. Across the East Antarctic plateau, regional
\end{abstract}

Correspondence to:

V. Masson-Delmotte

(valerie.masson@cea.fr) differences, with respect to the common East Antarctic signal, appear to have similar patterns during the current and last interglacials. We identify two abrupt shifts in isotopic records during the glacial inception at TALDICE and EDML, likely caused by regional sea ice expansion. These regional differences are discussed in terms of moisture origin and in terms of past changes in local elevation histories, which are compared to ice sheet model results. Our results suggest that elevation changes may contribute significantly to inter-site differences. These elevation changes may be underestimated by current ice sheet models.

\section{Introduction}

In the context of global warming, documenting past natural climatic variability in polar regions offers a benchmark against which to test Earth system models (Masson-Delmotte et al., 2006b). The current and last interglacial periods provide useful case studies to explore climate feedbacks in response to orbital forcing (NorthGRIP-community-members, 2004; Jouzel et al., 2007; Otto-Bliesner et al., 2006). The

Published by Copernicus Publications on behalf of the European Geosciences Union. 

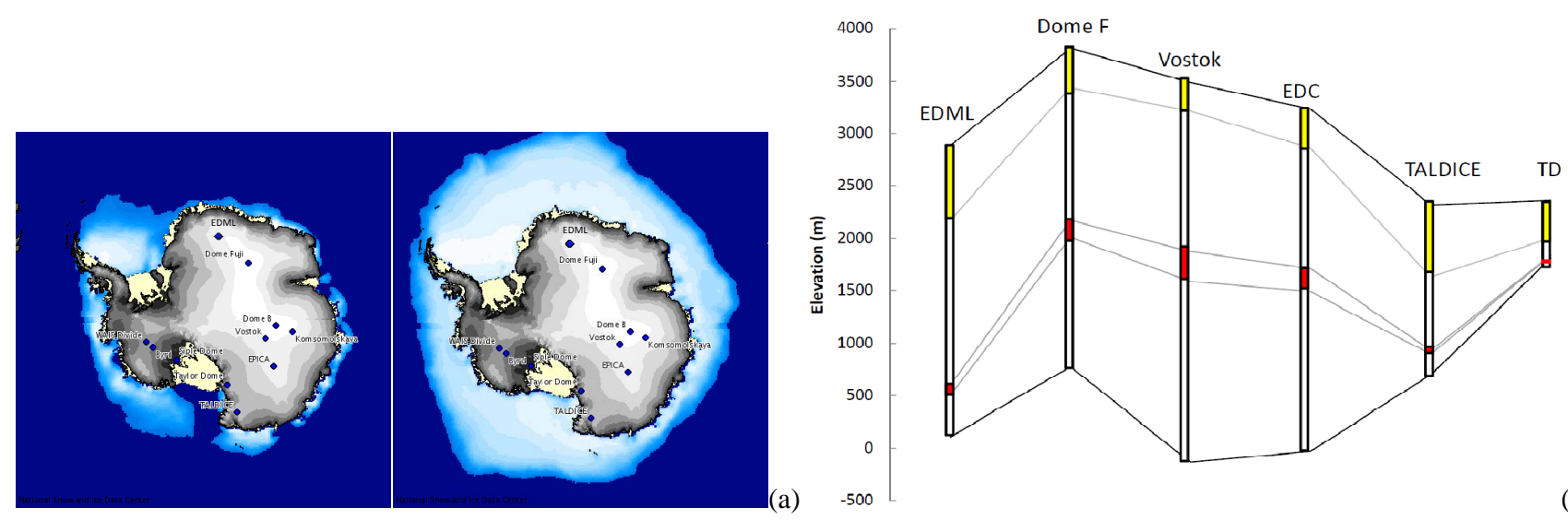

(b)

Fig. 1. (a) Location of deep drilling sites going back to MIS5.5: Vostok, Dome Fuji, EPICA Dome C (here labelled "EPICA") and Dronning Maud Land, Taylor Dome and TALDICE. The grey shading displays present day Antarctic elevation. The blue shading displays monthly mean sea ice concentration in February (left) and August (right). Maps were generated using the NSIDC software (http://www.nsidc.org). The distance from EPICA Dome C to Vostok is $560 \mathrm{~km}$, and from Vostok to Dome F $1500 \mathrm{~km}$. (b) Surface elevation (upper line), ice core depths (vertical rectangles) and position of the Holocene (yellow rectangles) and last interglacial (red rectangles) periods (as defined in Table 2, using EDC3 age scale for all records with the exception of TD). Note that the horizontal axis is not proportional to distance.

last interglacial period appears exceptionally warm in East Antarctica, in the context of the past $800 \mathrm{ka}$ (thousand of years) (Watanabe et al., 2003; Jouzel et al., 2007).

We focus here on the description of Antarctic climate variability, which can be documented in high resolution by ice core records of water isotopic composition (Masson et al., 2000). Ice core isotopic composition is affected by climate and water cycle variability through changes in evaporation conditions, air mass distillation history, and local condensation conditions including snowfall intermittency (Noone and Simmonds, 1998; Jouzel et al., 2003; Masson-Delmotte et al., 2006a; Sodemann and Stohl, 2009). Glaciological features can also affect ice core records through changes in local elevation (Vinther et al., 2009) and in ice origin (Huybrechts et al., 2007). The motivation of this study is to compare the temporal trends and the spatial variability of Antarctic ice core records of water isotopic composition for the present and past interglacial periods, which are now available from six Antarctic ice core sites (Table 1, Fig. 1), and to begin to identify the processes accounting for inter-site differences.

A previous comparison of eleven Antarctic ice core records spanning the Holocene period (Masson et al., 2000) has revealed robust features, such as the early Holocene optimum and millennial variability, but also different local or regional characteristics, especially in the Ross Sea sector. Since this synthesis effort, many new records have become available, such as the Siple Dome record in West Antarctica (Brook et al., 2005), two EPICA ice cores at Dome C (Jouzel et al., 2007) and Dronning Maud Land (EPICAcommunity-members, 2006), the Dome Fuji ice core (Watanabe et al., 2003), and the Taylor Dome (Grootes et al., 2001) and TALDICE ice cores in the Ross Sea sector (Stenni et al., 2011). The last five records also span the last interglacial, only covered by the Vostok (VK) core fifteen years ago (Jouzel et al., 1993).

Hereafter, we compare the present and last interglacial ice core water stable isotope records (0 to $145 \mathrm{ka}$ ) from the six available records, by historical order, Vostok, Dome F (hereafter DF), EPICA Dome C (EDC), EPICA Dronning Maud Land (EDML), Talos Dome ice core (TALDICE) and Taylor Dome ice core (TD) (Fig. 1, Table 1). All are located on the East Antarctic Plateau, at elevations between 2315 to $3810 \mathrm{~m}$, they face different ocean basins, with EDML and Dome F being situated in front of the Atlantic Sector, Vostok, EDC in front of the Indian Ocean sector and TD and TALDICE in the Ross Sea sector. Seasonal changes in sea ice cover are particularly large in the Atlantic and Ross sea sector (Fig. 1), potentially modifying the seasonal moisture origin for the nearby sites (Sodemann and Stohl, 2009). Present-day annual mean temperature ranges between -40 to $-57^{\circ} \mathrm{C}$ at these sites (Table 1). Most of our study focuses on the five ice core sites offering high resolution records of both the current and last interglacial periods, which is not the case for TD due to the strong compression of the last interglacial ice at this site (Fig. 1b, Table 2).

In Sect. 2, we introduce the orbital and deglacial contexts of the present and last interglacial, and the patterns and sequences of events previously identified by comparison of the EPICA Dome $\mathrm{C}$ records with climate reconstructions from other latitudes (Masson-Delmotte et al., 2010a). Section 3 describes the meteorological and glaciological contexts at the different sites. Section 4 presents the available stable isotope records from the ice cores, and the dating uncertainties. Section 5 analyses the similarities and differences between the 
Table 1. Site characteristics. Accumulation (Acc.) is given in mm water equivalent per year (equivalent to $1 \mathrm{~kg} \mathrm{~m}^{-2} \mathrm{yr}^{-1}$ ).

\begin{tabular}{|c|c|c|c|c|c|c|c|c|c|}
\hline Site & $\begin{array}{l}\text { Short } \\
\text { name }\end{array}$ & $\begin{array}{l}\text { Drilling } \\
\text { period }\end{array}$ & Latitude & Longitude & $\begin{array}{l}\text { Elevation } \\
\text { ma.s.l. }\end{array}$ & Mean annual temperature & Acc. & $10 \mathrm{~m}$ wind speed & Comments \\
\hline Vostok & VK & $\begin{array}{l}1982-1989 \\
\text { (Hole 3) }\end{array}$ & $78^{\circ} 28^{\prime} \mathrm{S}$ & $106^{\circ} 48^{\prime} \mathrm{E}$ & 3488 & $\begin{array}{l}-55.3^{\circ} \mathrm{C}(1958 \text { to } 2008 \text { with } \\
8 \text { missing years) } \\
\text { Seasonal amplitude: } 36.1^{\circ} \mathrm{C} \\
\text { (www.nerc-bas.ac.uk/icd/gjma/) }\end{array}$ & 21.5 & $\begin{array}{l}4.2 \mathrm{~m} \mathrm{~s}^{-1} \\
\text { www.aari.aq/stations/vostok/vostok_en.html }\end{array}$ & $\begin{array}{l}\text { Records for the Holocene have } \\
\text { been compiled from several shallow } \\
\text { cores (BH7, BH8). Records for the } \\
\text { LIG are provided by core 3G. }\end{array}$ \\
\hline EPICA Dome C & EDC & 1993-2004 & $75^{\circ} 06^{\prime} \mathrm{S}$ & $123^{\circ} 21^{\prime} \mathrm{E}$ & 3233 & $\begin{array}{l}-54.5^{\circ} \mathrm{C} \\
\text { Seasonal amplitude: } 34.9^{\circ} \mathrm{C} \\
\text { (www.meteoclimat.net) }\end{array}$ & $\sim 25$ & $\begin{array}{l}2.9 \mathrm{~m} \mathrm{~s}^{-1} \\
(1984-2003)\end{array}$ & $\begin{array}{l}\text { Records for the Holocene are from } \\
\text { core EDC } 96 \text { and for the LIG from } \\
\text { EDC } 99 .\end{array}$ \\
\hline $\begin{array}{l}\text { EPICA } \\
\text { Dronning } \\
\text { Maud Land } \\
\text { (Kohnen } \\
\text { Station) }\end{array}$ & EDML & $2001-2006$ & $75^{\circ} 00^{\prime} \mathrm{S}$ & $00^{\circ} 04^{\prime} \mathrm{E}$ & 2882 & $\begin{array}{l}-44.6^{\circ} \mathrm{C} \\
\text { Seasonal amplitude: } 26.9^{\circ} \mathrm{C}\end{array}$ & 64 & $\begin{array}{l}4.9 \mathrm{~m} \mathrm{~s}^{-1} \\
\text { M. van den Broeke (2010) }\end{array}$ & Main core data \\
\hline Talos Dome & TALDICE & $2004-2008$ & $72^{\circ} 49^{\prime} \mathrm{S}$ & $159^{\circ} 11^{\prime} \mathrm{E}$ & 2315 & $\begin{array}{l}-41^{\circ} \mathrm{C} \\
\text { Seasonal amplitude: } 24.5^{\circ} \mathrm{C} \\
\text { (AWS Priestley station) }\end{array}$ & 80 & $\begin{array}{l}\sim 4.5-5.1 \mathrm{~m} \mathrm{~s}^{-1} \\
\text { (M. Frezzotti, personal communication, 2010) }\end{array}$ & Main core data \\
\hline Dome Fuji & $\mathrm{DF}$ & $\begin{array}{l}1995-1996 \\
\text { and } \\
2003-2007\end{array}$ & $77^{\circ} 19^{\prime} \mathrm{S}$ & $39^{\circ} 40^{\prime} \mathrm{E}$ & 3810 & $\begin{array}{l}-57^{\circ} \mathrm{C} \\
\text { Seasonal amplitude: } \sim 40^{\circ} \mathrm{C} \\
\text { Fujita and Abe }(2006)\end{array}$ & 23 & $\begin{array}{l}5.4 \mathrm{~m} \mathrm{~s}^{-1} \\
\text { (http://polaris.nipr.ac.jp/ domef/home/eng/page4.html) }\end{array}$ & Records are from DF1 ice core. \\
\hline Taylor Dome & TD & 1993-1994 & $77^{\circ} 47^{\prime} \mathrm{S}$ & $158^{\circ} 43^{\prime} \mathrm{E}$ & 2365 & $-43^{\circ} \mathrm{C}$ & 50-70 & $?$ & Main core data \\
\hline
\end{tabular}

Table 2. Depth range where the present interglacial (in Antarctica, with EDC3 age scale, 0-12.1 kyr) and last interglacial (with EDC3 age scale, 116-132.6 kyr) ice is found in each deep ice core (in $\mathrm{m}$ ), mean number of years per $\mathrm{m}$ of ice for each ice core and each time period, and thinning ratio between the two interglacial periods (estimated here as the ratio between the number of last interglacial years per $\mathrm{m}$ of ice to the number of Holocene years per $m$ of ice). The beginning of last interglacial is found in the middle of the ice depth at DF (59\%), Vostok (52\%) and EDC (53\%) but closer to bedrock at EDML (86\%) and TALDICE (88\%). Thinning is minimum at Vostok, due to the impact of subglacial Lake Vostok on ice flow, and is maximum for TALDICE and Taylor Dome above a dry bedrock.

\begin{tabular}{|c|c|c|c|c|c|c|c|c|c|c|c|}
\hline & $\begin{array}{l}\text { Holocene } \\
\text { depth } \\
\text { range } \\
(0-12.2 \mathrm{ka} \\
\text { EDC3 })\end{array}$ & $\begin{array}{l}\text { Number } \\
\text { of } \\
\text { Holocene } \\
\text { years per } \\
\text { m of ice }\end{array}$ & $\begin{array}{l}\text { Holocene } \\
\text { sampling }\end{array}$ & $\begin{array}{l}\text { Holocene } \\
\text { resolution }\end{array}$ & $\begin{array}{l}\text { Last } \\
\text { interglacial } \\
\text { depth range } \\
\text { (116-132.6 } \\
\text { ka EDC3) }\end{array}$ & $\begin{array}{l}\text { Total ice } \\
\text { depth }\end{array}$ & $\begin{array}{l}\text { Last } \\
\text { interglacial } \\
\text { depth span }\end{array}$ & $\begin{array}{l}\text { Number of } \\
\text { Last } \\
\text { Interglacial } \\
\text { years per m } \\
\text { of ice }\end{array}$ & $\begin{array}{l}\text { Sampling } \\
\text { available }\end{array}$ & $\begin{array}{l}\text { Last } \\
\text { interglacial } \\
\text { resolution }\end{array}$ & $\begin{array}{l}\text { Thinning } \\
\text { ratio } \\
\text { between } \\
\text { Holocene } \\
\text { and last } \\
\text { interglacial }\end{array}$ \\
\hline DF & $0-372 \mathrm{~m}$ & $33 \mathrm{yr}$ & $\sim 0.25 \mathrm{~m}$ & $\sim 8 \mathrm{yr}$ & $1637-1800 \mathrm{~m}$ & $3035.2 \mathrm{~m}$ & $163 \mathrm{~m}$ & $102 \mathrm{yr}$ & $0.50 \mathrm{~m}$ & $\sim 50 \mathrm{yr}$ & 3.1 \\
\hline VOSTOK & $0-274 \mathrm{~m}$ & $\begin{array}{l}44 \mathrm{yr} \\
\text { between } 0\end{array}$ & $\begin{array}{l}0.50 \mathrm{~m} \\
\sim 220 \mathrm{yr} \\
\text { and } 138 \mathrm{~m} \\
(\mathrm{BH} 8) ; 5 \mathrm{~m} \\
\text { down to } \\
1413 \mathrm{~m} .\end{array}$ & $\sim 22 \mathrm{yr}$ & $1615-1903 \mathrm{~m}$ & $3623 \mathrm{~m}$ & $288 \mathrm{~m}$ & $58 \mathrm{yr}$ & $2 \mathrm{~m}$ & $\sim 115 \mathrm{yr}$ & 1.3 \\
\hline DC & $0-376 \mathrm{~m}$ & $32 \mathrm{yr}$ & $0.55 \mathrm{~m}$ & $\sim 18 \mathrm{yr}$ & $1524-1744 \mathrm{~m}$ & $3259.7 \mathrm{~m}$ & $220 \mathrm{~m}$ & $75 \mathrm{yr}$ & $0.55 \mathrm{~m}$ & $\sim 40 \mathrm{yr}$ & 2.3 \\
\hline EDML & 0-709m & $17 \mathrm{yr}$ & $0.50 \mathrm{~m}$ & $\sim 8 \mathrm{yr}$ & $2284-2381 \mathrm{~m}$ & $2774 \mathrm{~m}$ & $97 \mathrm{~m}$ & $171 \mathrm{yr}$ & $0.50 \mathrm{~m}$ & $\sim 85 \mathrm{yr}$ & 10.1 \\
\hline TALDICE & $0-691 \mathrm{~m}$ & $18 \mathrm{yr}$ & $1.0 \mathrm{~m}$ & $\sim 18 \mathrm{yr}$ & $1384-1419 \mathrm{~m}$ & $\begin{array}{l}1620 \mathrm{~m} \\
\text { (but } \\
\text { bedrock } \\
\text { not } \\
\text { reached) }\end{array}$ & $35 \mathrm{~m}$ & $490 \mathrm{yr}$ & $\begin{array}{l}1.0 \mathrm{~m} \\
0.05 \mathrm{~m}\end{array}$ & $\begin{array}{l}\sim 490 \mathrm{yr} \\
\sim 25 \mathrm{yr}\end{array}$ & 27.2 \\
\hline TD & $0-359 \mathrm{~m}$ & $34 \mathrm{y}$ & $\sim 0.15 \mathrm{~m}$ & $\sim 5 \mathrm{yr}$ & $525-530 \mathrm{~m}$ & $554 \mathrm{~m}$ & $5 \mathrm{~m}$ & $\sim 750 \mathrm{yr}$ & $\sim 0.22 \mathrm{~cm}$ & $\sim 740 \mathrm{yr}$ & 22.1 \\
\hline
\end{tabular}

present and last interglacials and among the ice core records, using different methods. A strong homogeneity is depicted, as well as site-specific anomalies which have similar patterns during the present and last interglacial. We examine the potential sources of biases linked with changes in moisture origin, using the available deuterium excess - based temperature reconstructions. We finally compare the stable isotope anomaly specific to each deep drilling site with past elevation reconstructions derived from ice flow models, before a summary of our results and their implications (Sect. 6) is given. 


\section{Orbital and deglacial contexts for the present and last interglacials}

The present (Holocene or Marine Isotopic Stage 1) and last interglacial period (Marine Isotopic Stage 5.5, or Eemian) (Shackleton et al., 2003) has occured under different orbital hereafter also noted LIG for last interglacial configurations and has exhibited different mean climatic levels, amplitudes and trends at different latitudes (Masson-Delmotte et al., 2010a) (Fig. 6b and c). Eccentricity has been much stronger during the last interglacial than during the Holocene, enhancing, the impact of precession and seasonal contrasts. The phase between precession and obliquity has also been different. During this last interglacial, obliquity reached its maximum at $131 \mathrm{kyr}$ (thousand of years before present) followed by a minimum in the precession parameter at $127 \mathrm{kyr}$, while the Holocene precession parameter minimum occurred at $12 \mathrm{kyr}$, followed by an obliquity maximum at $10-9 \mathrm{kyr}$. While the orbital configuration is well known, the exact mechanisms relating changes in Antarctic climate and orbital parameters remain controversial, with ice core studies pointing to a link with Northern Hemisphere summer insolation (Kawamura et al., 2007), albeit with large lags with respect to precession and obliquity (Jouzel et al., 2007), and modelling studies pointing to the importance of local seasonal insolation (Huybers and Denton, 2008; Timmermann et al., 2009) and possible biases due to changes in accumulation seasonality (Huybers, 2009). The present and last interglacial periods offer the possibility to explore the response of climate to orbital forcing with roughly comparable contexts in terms of ice volume (Bintanja et al., 2005) and greenhouse gas concentrations (Siegenthaler et al., 2005; Loulergue et al., 2008), two of the major feedbacks at play during glacial-interglacial transitions (Hansen et al., 2008; MassonDelmotte et al., 2010a).

The onset of the current interglacial in Greenland has been precisely dated thanks to the GICC05 annual layer counting on Greenland ice cores (Rasmussen et al., 2006). The abrupt warming ending the Younger Dryas cold period is recorded at 11703 years before year $2000 \mathrm{~A}$ (Vinther et al., 2006). In Antarctic ice cores, several parameters can be used to detect the onset and end of warm intervals: records of local climate in ice core $\delta^{18} \mathrm{O}$ or $\delta \mathrm{D}$, records of sea salt or terrestrial aerosol deposition reflecting regional climate conditions (in relationship with the sources of sea salt or dust and transportation) in ice core chemistry, or records of global atmospheric composition. In the EPICA Dome $\mathrm{C}$ ice core, a $\delta \mathrm{D}$ threshold of $-403 \%$ (Holocene average) (EPICA-community-members, 2004) to $-405 \%$ o (threshold marking the end of the glacial correlation between dust flux and EDC $\delta \mathrm{D}, 10 \%$ below the late Holocene $\delta \mathrm{D}$ average) (Röthlisberger et al., 2008; Petit and Delmonte, 2009) was defined as the lower limit of an interglacial. Using a threshold of $-405 \%$ on EDC $\delta$ D and the EDC 3 age scale (Parrenin et al., 2007a) leads to an onset of the Antarctic present day interglacial at $12.2 \mathrm{kyr}(1950 \mathrm{AD}$, or Before Present), therefore about 500-600 years before the onset of the Holocene recorded in Greenland ice cores, and the parallel atmospheric $\mathrm{CH}_{4}$ concentration rise (Severinghaus and Brook, 1999). During the last interglacial, the EDC final abrupt methane increase is dated at $\sim 128.6 \mathrm{kyr}$, while $\delta \mathrm{D}$ crosses the "interglacial" threshold at $\sim 132.4 \mathrm{kyr}$ ( $3.8 \mathrm{ka}$ earlier) and at $\sim 116 \mathrm{kyr}$, when the glacial inception appears in phase between northern and southern high latitudes (Landais et al., 2005). There are therefore differences between the timing of the onset of warm Antarctic intervals and the timing of interglacial periods as seen from the Northern Hemisphere, and the early part of "Antarctic interglacial periods" are known to be still affected by the final decay of glacial ice sheets and associated changes in freshwater flux (Debret et al., 2009; Renssen et al., 2010).

Atmospheric general circulation models equipped with water stable isotopes have been extensively used to explore the climatic controls on present day and glacial Antarctic snowfall isotopic composition, and, so far, have simulated a rather constant isotope-temperature relationship in Central East Antarctica between glacial and present-day conditions (Jouzel et al., 2007). Due to the difficulty of simulating past climates warmer than today in central Antarctica in response to changes in orbital forcing (Overpeck et al., 2006; Masson-Delmotte et al., 2010b), only few modelling studies have been dedicated to the stability of the isotopetemperature relationship under warmer conditions (Schmidt et al., 2007; Sime et al., 2008). The Dome C, Vostok and Dome Fuji ice core records spanning the last 340 ka were compared and model simulations were used to propose explanations for the differences amongst the records (Sime et al., 2009b). Their climate projections showed relatively homogeneous temperature change induced by the A1B projection scenario across the three long East Antarctic ice-cores sites. This, alongside with the comparison of ice core records and isotopic modelling, led them to interpret the differences in stable isotope ratios as reflecting changes in the isotopetemperature relationships, especially between Dome Fuji and Dome C. This work points to non-linearities in some of the isotope-temperature relationships, and to some uncertainty in the individual core isotope-temperature conversions. They concluded that peak Antarctic temperatures during the last interglacial could have been more than $6^{\circ} \mathrm{C}$ above presentday. However, we note that an increased $\mathrm{CO}_{2}$ warming scenario is an imperfect analogue for the boundary conditions of past interglacials.

It has been argued (Masson et al., 2000; Masson-Delmotte et al., 2010a) that the early Holocene and last interglacial optima recorded in EPICA Dome $\mathrm{C}$ isotopic records are caused by a bipolar see-saw pattern occurring under interglacial contexts and caused by the Northern Hemisphere ice sheet deglacial history, similarly to glacial Antarctic Isotopic Maxima (Capron et al., 2010). As the deglacial freshwater feedback is not part of standard climate simulations, this may 
be the reason why climate models do not simulate any significant annual mean Antarctic warming during the last interglacial unless they take into account Greenland ice sheet meltwater (Masson-Delmotte et al., 2010b). Recent simulations show Antarctic warming reaching $1-2{ }^{\circ} \mathrm{C}$ and larger at Dome $\mathrm{F}$ than at Dome $\mathrm{C}$, in response to freshwater forcing during the last interglacial. The simulated Antarctic warming can reach up to $5^{\circ} \mathrm{C}$ warming in response to both freshwater forcing and to the removal of the West Antarctic Ice Sheet (Holden et al., 2010), suggesting that changes in Antarctic topography may also be significant. Northern Hemisphere deglacial feedbacks are also expected to be at play during the early Holocene optimum (or Antarctic Isotopic Maximum number 0) (Masson-Delmotte et al., 2010a). The question of changes in topography is one motivation for exploring past differences between ice core records.

\section{Deep drilling sites: climatological and glaciological characteristics}

The six deep drilling locations are all situated in the central East Antarctic Plateau, at elevations varying from $2315 \mathrm{~m}$ to $3810 \mathrm{~m}$ a.s.l. (above sea level). They have different modern climatological backgrounds, with an annual mean temperature between $-40^{\circ} \mathrm{C}$ and $-57^{\circ} \mathrm{C}$, and a modern accumulation rate beween $\sim 21$ and $80 \mathrm{~mm}$ per year $(1 \mathrm{~mm}$ water equivalent per year corresponds to $\left.1 \mathrm{~kg} \mathrm{~m}^{-2} \mathrm{yr}^{-1}\right)$. Differences between the sites arise from their latitude (and insolation), elevation, distance to the nearest open ocean, and from atmospheric heat and moisture advection.

In this section, we first describe the present day climatological context of different deep drilling sites in terms of precipitation regimes (Sect. 3.1), moisture origins (Sect. 3.2), the importance of precipitation intermittency for the archiving of temperature variability in ice cores (Sect. 3.3), and finally the ice flow contexts for the deep drilling sites (Sect. 3.4). These characteristics will be used in Sect. 5 when assessing the different processes which can explain differences between deep ice core records from different East Antarctic sectors.

\subsection{Precipitation regimes of the ice core site locations}

For a correct ice core interpretation it is highly important to understand the precipitation regime of the drilling location. In the interior of the continent on the majority of days, only clear-sky precipitation ("diamond dust") is observed. However, the amount of accumulation from diamond dust is extremely low. In recent years, increasing evidence has been found that also on the high east Antarctic plateau precipitation events occur that yield precipitation amounts one or two orders of magnitude larger than diamond dust. Although such events occur only a few times per year, they can thus bring a substantial part of the total yearly accumulation. In most cases, such events are connected to an amplification of Rossby waves that leads to increased meridional flow patterns (e.g. Schlosser et al., 2010a). This means advection of relatively warm and moist air from lower latitudes to the continent, which is then orographically lifted and cooled, delivering high precipitation amounts.

Several studies were conducted for the EDML drilling site, Kohnen Station (Schlosser et al., 2008, 2010a,b; Birnbaum et al., 2006). Whereas Birnbaum et al. (2006) investigated only a restricted number of cases observed during summer campaigns using ECMWF data, Schlosser et al. (2008, 2010a) used data from the Antarctic Mesoscale Prediction System (AMPS) (Powers et al., 2003) to investigate the characteristics of such "high-precipitation events" between 2001 and 2006. They found that only $20 \%$ of the events were directly caused by frontal systems of passing cyclones in the circumpolar trough, the vast majority of the events being connected to advection of warm air by amplified Rossby waves. They estimated the ratio of diamond dust to synoptic precipitation at the EDML site to be $40 \%$ to $54 \%$.

At Dome Fuji, in eastern Dronning Maud Land (DML), at an altitude almost $1000 \mathrm{~m}$ higher than Kohnen Station, the same mechanisms have been observed. Enomoto et al. (1998) and Hirasawa et al. (2000) studied meteorological conditions at Dome Fuji. In particular, they investigated blocking anticyclones in winter, which were found to be able to change meteorological conditions considerably by advection of warm air that led to cloud formation. This increased the downward long-wave atmospheric radiation, destroying the inversion layer and thus dramatically changing temperatures. However, it was not in all cases that humidity of the advected air was sufficient to produce precipitation. Fujita and Abe (2006) carried out daily precipitation measurements at Dome Fuji during a period of approximately 12 months during their wintering in 2003/2004. They estimated the amount of diamond dust compared to synoptically induced precipitation to $52 \%$ of the total precipitation, which is in close agreement with Schlosser et al. (2010a), who estimated a value of 55\% using AMPS archive data. The EDML drilling site and Dome Fuji can get precipitation from the same blocking high (Schlosser et al., 2010b), but usually, Dome Fuji would get precipitation from a blocking situation linked with an anticyclone situated above the more eastern parts of DML. Suzuki et al. (2008) investigated moisture sources for Dome Fuji by calculating 5-day backward trajectories using ERA40 reanalysis data. They also found that snowfall conditions were often connected to high-pressure ridges that force moist air from the Atlantic and Indian Oceans to move over the continent to Dome Fuji.

Vostok is situated slightly further south than Dome Fuji, but at an altitude about $300 \mathrm{~m}$ lower. The climatological mean annual temperatures are comparable, within $2^{\circ} \mathrm{C}$. Changes in accumulation rate and isotopic composition were studied in the snow of Vostok (Ekaykin et al., 2004), using monthly accumulation from stake measurements and 
meteorological observations. These authors compared months with and without precipitation from clouds and thus estimated the amount of diamond dust to approximately $75 \%$ of the total precipitation, albeit with large uncertainties (59 to $91 \%$ ). In spite of this relatively low fraction of synoptically induced precipitation, they explain the observed changes in accumulation rate and isotope ratio over several decades by changes in cyclonic activity.

For Dome C, daily precipitation measurements are not available yet. Being located at the same latitude as Kohnen Station, it is nevertheless situated considerably farther away from the coast and at an approximately $300 \mathrm{~m}$ higher altitude. Massom et al. (2004) investigated the precipitation regime of the Dome $\mathrm{C}$ and Law Dome areas using satellite imagery, AWS data, and ECMWF model data. Their results show that intermittent blocking-anticyclone events in the South Tasman Sea can cause significant precipitation events on the East Antarctic ice sheet, but no firm conclusions have been drawn about their contribution to the total precipitation amount. They further note that not only blocking situations, but also slowly moving cyclones offshore can cause significant individual precipitation events. They diagnosed a moisture origin between $40^{\circ} \mathrm{S}$ and $35^{\circ} \mathrm{S}$, which is consistent with moisture trajectories (Sodemann and Stohl, 2009) discussed later in our Sect. 3.2, and with Rayleigh isotopic modelling (Stenni et al., 2001).

Talos Dome is by far the lowest drilling site, and it has the shortest distance to the coast and also the highest accumulation rate $(80 \mathrm{~mm})$. (Scarchilli et al., 2010) investigated precipitation conditions at Dome $\mathrm{C}$ and Talos Dome. They also found that high-precipitation events are often caused by blocking anticyclones, leading to increased moisture transport towards the drilling sites. Talos Dome is influenced by moisture originating mainly from the Indian Ocean and secondarily from Pacific sectors of the Southern Ocean. Snow precipitation originating from the Indian Ocean falls mainly during winter $(70 \%)$, whereas the snowfall events originating from the Pacific Ocean/Ross Sea are more homogenously distributed during the year (50\% in winter, $50 \%$ in summer). The snowfall events originating from the Pacific Ocean arrive at Talos/Taylor Dome mainly via the Ross Sea, where the extensive presence of sea ice also occurs during summer. Longer and cooler distillation pathways of these air mass trajectories are expected to produce more negative $\delta^{18} \mathrm{O}$ precipitation values at TD compared to the ones originating from the Indian Ocean. During the Last Glacial Maximum (LGM) and most of the deglaciation, due to the presence of the Ross Ice Sheet extending up to the continental margin, the transport of moisture from the Pacific sector via the Ross Sea was very likely drastically reduced and compensated by an increase in the transport of moisture from the Indian Ocean sector (Stenni et al., 2011; Scarchilli et al., 2010).

At the inter-annual scale, the occurrence of highprecipitation events is strongly connected to the Southern Annular Mode (SAM), which is the dominant mode of climate variability at high latitudes in the Southern Hemisphere (Marshall, 2003). When the SAM is in its positive phase, the circumpolar westerlies are strong due to the large north-south air pressure gradient, which means a highly zonal flow with little meridional exchange of heat and moisture. A negative phase of the SAM, however, means weaker westerlies above the polar ocean and a more meridional flow due to amplified Rossby waves, which favours the formation of blocking highs that lead to the precipitation events mentioned earlier. Generally, an East Antarctic cooling is observed during periods with strongly positive SAM and a warming when SAM is negative (Kwok and Comiso, 2002; Marshall, 2007).

The East Antarctic ice core stable isotope records depict periods with stable isotope values less depleted than today, suggesting warmer conditions (Masson-Delmotte et al., 2010b). If past warm conditions were marked by a negative SAM, one would expect a higher frequency of the previously described blocking events and a larger contribution of high-precipitation events to the total accumulation. Climate projections under scenarios of increased greenhouse gas concentrations and stratospheric ozone depletion point by contrast to a more positive SAM (IPCC, 2007) (Sect. 10.3.5.6). While ice cores may offer the potential to depict past SAM variations (Divine et al., 2009), information about SAM may be needed for the quantitative interpretation of the ice core data. The SAM itself is strongly connected to ENSO; however, the interaction between SAM and ENSO is highly nonlinear and not fully understood yet. There is evidence that it varies temporally (Genthon and Cosme, 2003; Fogt and Bromwich, 2006), since it additionally depends on tropical forcings.

\subsection{Moisture sources of precipitation}

Backward trajectories calculated from atmospheric reanalysis products have been used in a number of studies to characterize the origin of East Antarctic air masses and water vapor for precipitation. A first comprehensive study for several drilling locations focussed on snowfall days and suggested a dominant (30\% of precipitation) austral moisture source $\left(50-60^{\circ} \mathrm{S}\right)$ together with significant seasonal and inter-annual variability (Reijmer et al., 2002). However, East Antarctic precipitation was seriously underestimated in this approach. Field studies indeed have revealed a strong contribution of clear sky precipitation to surface mass balance at Vostok (Ekaykin, 2003) and DF (Fujita and Abe, 2006). Moreover, isotope modelling studies and water tagging simulations in general circulation models both have suggested a more distant moisture origin (Delaygue et al., 2000a; Masson-Delmotte et al., 2008; Werner et al., 2001).

More recently, a quantitative moisture source diagnostic has been developed (Sodemann et al., 2008). Backward calculations were conducted on long periods (20 days) as compared to the commonly applied 5-day calculation period 
used in previous studies. Moisture sources from precipitating air parcels were diagnosed at a $6 \mathrm{~h}$ interval in a $100 \mathrm{~km}$ radius around each drilling site. Monthly mean moisture sources for each ice core site were then calculated from a precipitation-weighted average of the evaporation-weighted mean moisture source latitude and longitude diagnosed from each tracked air parcel. This moisture source diagnostic was applied in conjunction with a Lagrangian particle dispersion model to Antarctica, covering a period from October 1999 to April 2005, using ECMWF analysis data (Sodemann and Stohl, 2009). For the calculation setup, the global atmosphere was three-dimensionally subdivided into 1.4 million particles of equal mass that were traced forward over the 5year calculation period. The subset of air parcels for which moisture origin was considered here were selected when specific humidity anywhere over Antarctica (land mass south of $60^{\circ} \mathrm{S}$ ) decreased by more than $0.1 \mathrm{~g} \mathrm{~kg}^{-1}$ when relative humidity was greater than $80 \%$ over Antarctica. Note that parcels can be located at any altitude within the atmosphere. Under these conditions it was assumed that a precipitating cloud is present in the model atmosphere. For the particles selected by these criteria, moisture source regions were detected as the regions where specific humidity increased by more than $0.1 \mathrm{~g} \mathrm{~kg}^{-1}$ within the marine boundary layer, weighted under consideration of the temporal sequence of precipitation and evaporation events along the trajectory. The method is described in further details in (Sodemann et al., 2008) and (Sodemann and Stohl, 2009). This 5-year climatology of Antarctic moisture origin shows more distant moisture sources than from previous back-trajectory based studies, the results being consistent with water tagging simulations and isotope modeling in GCMs (Delaygue et al., 2000b; Werner et al., 2001). In this analysis, we have focussed on the average moisture source, calculated for the period 19992005. Due to the length of analysis, we could not address the drivers of inter-annual, decadal or longer time scale changes in moisture origin, for instance in relationship with the SAM.

Figure 2 displays the results of this calculation in terms of the mean and standard deviation of moisture source latitude and longitude for the three month periods associated with maximum (August-September-October, ASO) and minimum (January-February-March, JFM) Antarctic sea ice extent for our six drilling locations. The central East Antarctic Plateau sites (Vostok, DF and EDC) show rather consistent moisture origin, with an annual mean moisture source located around $42^{\circ} \mathrm{S}$ (not shown), shifting $\sim 2^{\circ} \mathrm{S}$ in summerautumn (JFM), possibly in relationship with the reduced sea ice cover. The inter-site differences remain within the limits of the seasonal mean variability spread of intra to inter-annual moisture sources. Because sea surface temperature acts on kinetic fractionation at evaporation (Merlivat and Jouzel, 1979), warmer (and more northward) moisture sources are expected to produce higher deuterium excess levels in Antarctic snowfall. The highest modern deuterium excess levels are encountered at Dome F (Uemura et al.,
2004; Masson-Delmotte et al., 2008) and cannot be simply explained by our analysis showing rather comparable moisture source latitudes for the central plateau. We note that deuterium excess is also affected by other evaporation conditions such as relative humidity (Uemura et al., 2008), transport and distillation effects (colder Dome F conditions are expected to induce higher deuterium excess) and intermittency of precipitation. The moisture source calculation is also associated with relatively large uncertainty and should be more firmly established, e.g. by considering a longer climatology. Because this comparison between mean deuterium excess and moisture source calculations is inconclusive (due to the overlap of the mean moisture sources for the central East Antarctic ice core sites), further investigations will need to compare the isotopic composition of snowfall on an event basis (Fujita and Abe, 2006) at different sites with daily moisture origin calculations.

Differences clearly appear between the "highest elevation sites" (Vostok, DF and EDC) and the "lower elevation" drilling sites (EDML, Taylor Dome and TALDICE). On the annual mean, TALDICE and EDML share a moisture origin at $\sim 45^{\circ} \mathrm{S}$ (not shown), while the moisture source of Taylor Dome is located further south at $\sim 52^{\circ} \mathrm{S}$. However, marked seasonal differences appear: in winter (ASO), TALDICE has a moisture source similar to the inland sites, but EDML exhibits a $\sim 45^{\circ} \mathrm{S}$ moisture origin, which contrasts with the large Atlantic sector maximum sea-ice cover (Figs. 1 and 2a), and Taylor Dome appears to receive moisture from $\sim 49^{\circ} \mathrm{S}$. In summer (JFM), TD and TALDICE are the exceptions, showing the most southward moisture origins. In the Ross Sea area, the dominant moisture source longitude appears shifted westwards in summer with respect to winter, a feature much stronger for TD than for TALDICE (Sodemann and Stohl, 2009; Scarchilli et al., 2010). This anomaly could be due to the topographic configuration of the Ross Sea and to the cyclogenesis from the sea-ice free Ross Sea sector, with the strongest distance of moisture transport for Taylor Dome.

At the scale of Antarctica, coastal/ice sheet margin areas undergo minimum seasonal shifts in moisture source (Fig. 2c). By contrast, the inner sector of East Antarctica and the Ross Sea sector (including TALDICE and Taylor Dome) exhibit the strongest seasonality in moisture source location. Both elevation and distance to the open ocean therefore seem to affect the seasonal shifts in moisture origin. The precise links between the seasonality of moisture origin and the isotopic records are difficult to assess due to the low accumulation at most of the ice core sites and the lack of seasonal resolution (Tables 1 and 2).

Ice core records obtained from our different drilling sites are therefore expected to reflect changes in local site characteristics (accumulation, condensation temperature sampled through precipitation intermittency) and features linked with the initial ocean basin where the moisture is formed. During the last glacial periods and the last termination, the Antarctic Isotopic Maxima (AIM) have different shapes in EDC 

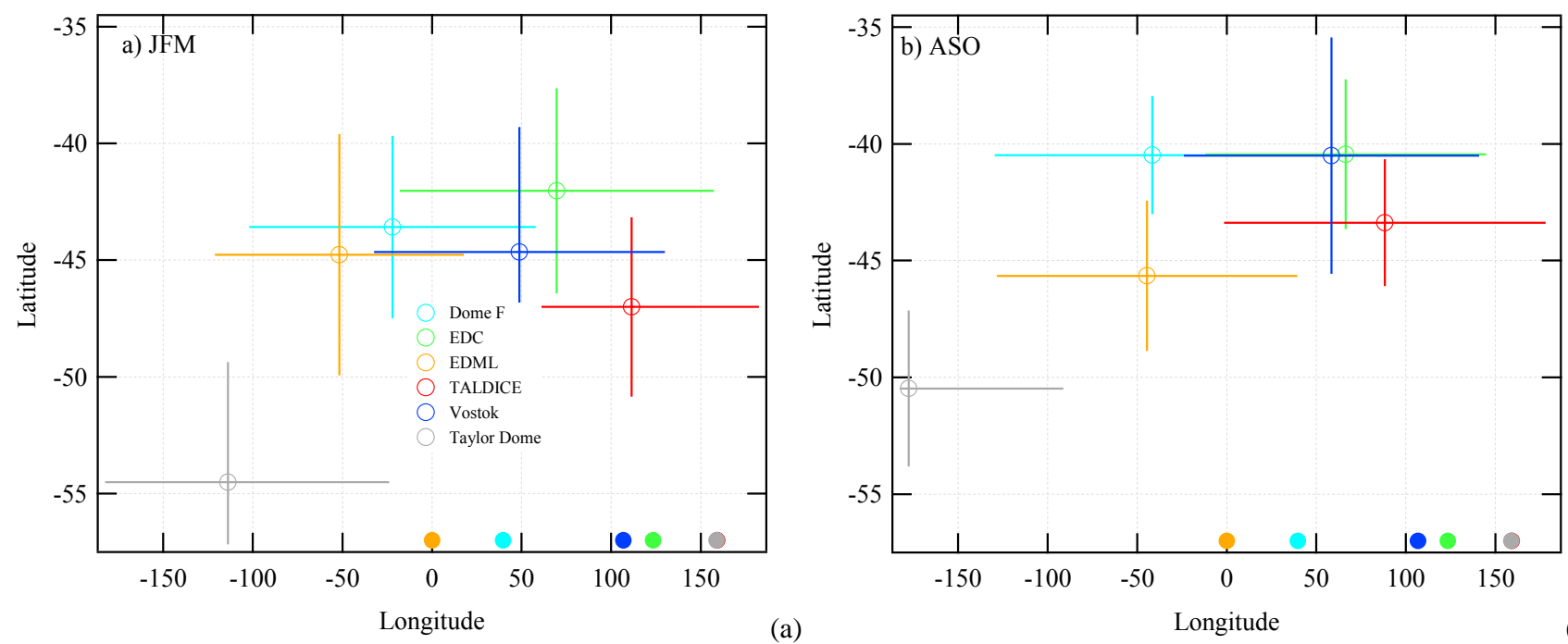

(b)

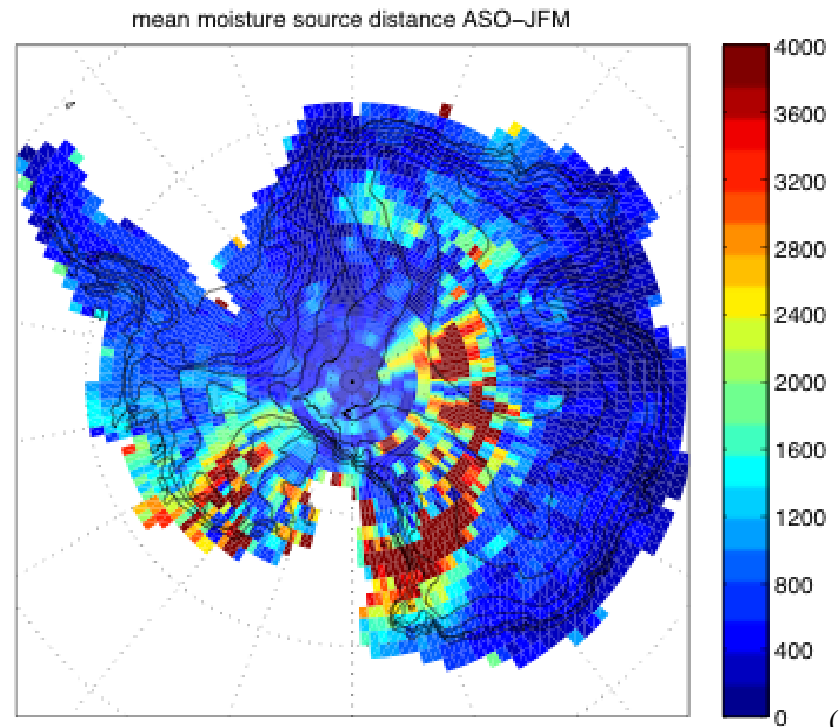

(c)

Fig. 2. Moisture origin calculated from ECMWF analysis data using a Lagrangian moisture source diagnostic and extracted for two three- month periods linked with maximum and minimum Antarctic sea ice cover - (a) JFM, January-February-March, and (b) ASO, August-September-October, for the six deep drilling locations studied here (Dome F, EDC, EDML, TD, TALDICE and Vostok). The longitude of each drilling site is displayed with a filled circle on the horizontal axis (the grey and red circles for TD and TALDICE are overlapping each other). The mean moisture source latitude and longitude is displayed with an open circle. Error bars depict the standard deviation of the source latitude and longitude calculated (precipitation-weighted) from the monthly mean values (themselves based on 6-hourly trajectories), for each season, for the grid points within a $100 \mathrm{~km}$ radius around each ice core site. (c) Missing mean seasonal amplitude of the moisture source shifts, indicated by the distance $(\mathrm{km})$ between the ASO and JFM mean moisture source location from the Lagrangian moisture source diagnostic (Sodemann and Stohl, 2009).

and TALDICE, receiving moisture from the Indo-Pacific sector, and EDML, receiving moisture from the Atlantic sector (Stenni et al., 2010b; Stenni et al., 2011). In Sect. 5, we will discuss if inter-site differences in interglacial trends can be attributed to regional changes in moisture sources thanks to the available deuterium-excess data.

\subsection{Impact of precipitation intermittency on temperature recording}

Water stable isotope records from deep ice cores can only archive climate information at times when precipitation occurs. This section is focussed on the impact of precipitation intermittency on the temperature information archived in ice cores, and makes use of atmospheric reanalyses to quantify the regional differences in this potential bias. 
ECMWF ERA40 reanalysis is considered reliable for both temperature and precipitation across much of Antarctica from 1980 onwards (Miles et al., 2008; Marshall, 2009). Mean annual temperature and precipitation from 22 years (1980-2002) of ECMWF ERA40 data are shown in Fig. 3a. The ERA40 data can be used to characterize precipitation intermittency (at the synoptic to seasonal scales) and its impact on the archiving of temperature information in stable isotope records from deep ice cores. One study showed that reanalysis captures the seasonal cycle of coastal Antarctic precipitation well, but that it may overestimate the amount of central East Antarctic summer precipitation (Marshall, 2009).

The effect of covariance between temperature and precipitation on the recorded ice core temperature can be investigated by calculating the precipitation-weighted temperature (Steig et al., 1994; Krinner et al., 1997; Werner and Heimann, 2002; Krinner and Werner, 2003; Sime et al., 2008, 2009a,b). This signal can moreover be decomposed into the sum of a high-pass filtered component capturing synoptic scale covariance ( $<60$ days) and one low-pass filtered component capturing seasonal scale covariance (60-375 days) (Sime et al., 2008, 2009a).

Figure 3b-d shows the 1980-2002 temperature "biasing" effect, that is the mean temperature minus the precipitationweighted temperature due respectively to total, seasonal, and synoptic temperature and precipitation covariance (Sime et al., 2008, 2009b). The results are quite similar to those obtained for present-day biasing from HadAM3 (Sime et al., 2008). They allow us to quantify the degree to which Antarctic precipitation occurs under warmer-than-average conditions. Interesting features of the results are (1) the strong seasonal biasing effect is largely restricted to central East Antarctic regions; (2) the synoptic biasing term is significantly larger than the seasonal effect for most of Antarctica, and is very large in coastal regions; and (3) the total size of the biasing is quite large, between 6 and $8.5 \mathrm{~K}$, for most of East Antarctica. This bias reflects warmer temperatures during snowfall events in East Antarctica. This is presumably due to the relationship between heat and moisture advection, and perhaps also to local radiative feedbacks linked with increased moisture and cloudiness (Gallée and Gorodetskaya, 2008). The large size of the biasing terms means that rather small percentage changes in the biasing, during a climate shift, can have rather large effects on the temperatureisotope relationship across Antarctica. We note for the deep ice core sites of interest here, that the seasonal bias seems slightly larger for Dome C and Vostok than for Dome F, and that the synoptic bias appears stronger for EDML than for TALDICE.

Annual mean temperature and annual mean precipitationweighted temperature (using daily mean data) were calculated across Antarctica from 1980-2002 data. Using only grid points south of $60^{\circ} \mathrm{S}$, this gives 2581 time series of 22 years (where each year is represented by a single value), on an approximately equal area grid, with an approximate

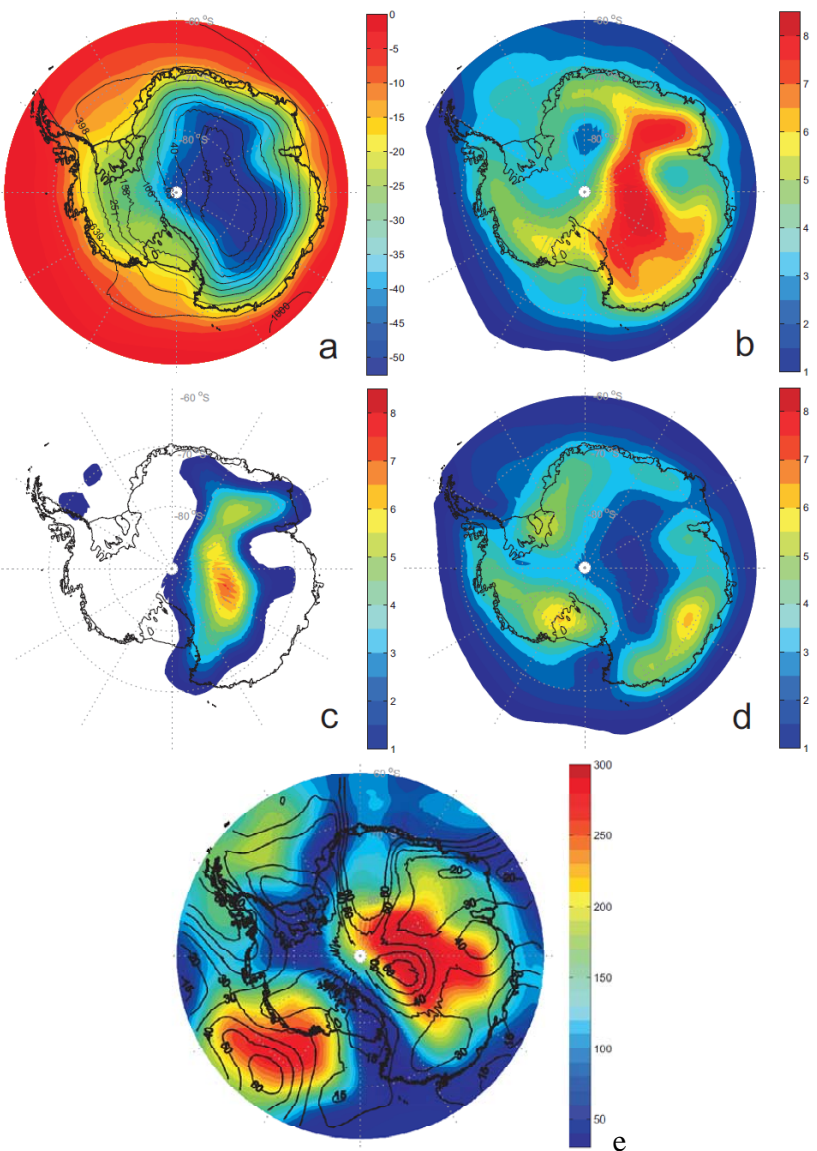

Fig. 3. Panel (a) shows the mean annual $2 \mathrm{~m}$ air temperature (shaded) and precipitation (contours show $\mathrm{kg} \mathrm{m}^{-2} \mathrm{yr}^{-1}$ equal to $\mathrm{mm} \mathrm{yr}^{-1}$ water equivalent) on a logarithmic interval scale) of 22 years (1980-2002) of ECMWF ERA40 data. Panels (b-d) show the biasing anomaly, i.e. the difference between temperature weighted by precipitation and mean annual temperature. Panel (b) is total biasing (covariance of all frequency temperature and precipitation), contoured at $0.5 \mathrm{~K}$ intervals; panel (c) is the seasonal (60-375 day biasing signal); and panel (d) is synoptic ( $<60$ days biasing signal). All data are presented using a $400 \mathrm{~km}$ averaging radius (see Sime et al., 2008). (e) The regional coherency of ERA40 inter-annual temperature and precipitation-weighted temperature changes. The colour scale displays the number of locations with correlated time-series $(R>0.75,22$ years $)$ of temperature (shaded) and precipitation-weighted temperature (contoured) for each grid point.

grid spacing of $100 \mathrm{~km}$. Cross-correlating all 2581 time series provided information on the regional coherency of interannual temperature and precipitation-weighted temperature changes (Fig. 3e). The regional coherency is depicted by contouring the number of grid points which exceed an arbitrary correlation value, chosen to be $R=0.75$ (Fig. 3). We note that a similar pattern also emerges for higher correlation threshold values. As such, this pattern seems to depict a robust picture of regional coherency in inter-annual variations in temperature. 
Inter-annual changes in temperature and precipitationweighted temperature are highly coherent across the East Antarctic plateau region (Fig. 3e). This coherency is stronger in temperature than in precipitation-weighted temperature. Both temperature and precipitation-weighted temperature show a sharp decline in regional coherency in a band which stretches across West Antarctica, extending across the TALDICE region. There is a slight increase in coherency across the Siple Dome area, and also across the west side of the Antarctic Peninsula. We emphasise that these results are obtained from a rather short 22 year ERA40 time-series, and their validity at longer time scales remains to be explored. The reanalyses suggests that temperature or precipitationweighted temperature in the TD/TALDICE sector may not be expected to be coherent with the central East Antarctic Plateau. Finally, we note that windy areas across Antarctica, including in the region of Talos Dome, are also subject to high levels of surface snow sublimation (Frezzotti et al., 2004). During past warm episodes, changes in sublimation rates across core sites could introduce further additional regional variation into the ice core records. This is not pursued further in this present work.

The importance of precipitation intermittency has been highlighted on a variety of time scales (decadal variability, response to orbital forcing, response to greenhouse gas concentration increases). Using an atmospheric general circulation model equipped with water stable isotopes, (Sime et al., 2008) have shown that, in response to increased greenhouse gas concentrations, the simulated temperature-isotope temporal slope is weaker than the spatial slope at Dome F or EDML, and is about $40 \%$ of the spatial slope near Dome C and Vostok. The low temporal slope is mostly caused by changes in precipitation intermittency under warmer projected climates (Krinner et al., 2007) highlighted a stronger increased greenhouse gas concentrations response in central versus coastal East Antarctica (possibly linked with an increased frequency of cloud cover days), and a minimum precipitation weighting bias near the Dome F area. Finally, Schmidt et al. (2007) explored the temporal isotopetemperature relationship in Antarctic precipitation using a coupled ocean-atmosphere model equipped with the explicit modelling of stable isotopes, at the inter-annual scale but also during mid-Holocene, in response to changes in orbital forcing. In all of their simulations, the temporal East Antarctic slope $\left(0.2-0.5 \%\right.$ of $\delta^{18} \mathrm{O}$ per $\left.{ }^{\circ} \mathrm{C}\right)$ appears systematically weaker than the present-day modern slope, but they did not analyse the regional differences or the reasons for the weaker temporal slope.

The available modelling framework therefore quantifies how precipitation intermittency affects temperature reconstructions based on ice core records of precipitation isotopic composition. The results suggest that, during interglacial periods, this precipitation intermittency effect can be different among sites on the East Antarctic plateau, and between the East Antarctic plateau and the TD/TALDICE area.
Over the time scales explored here (inter-annual variability, mid Holocene, increased greenhouse gas concentrations), the model results suggest rather coherent temperature anomalies in the East Antarctic sector, as well as a weaker isotopetemperature temporal gradient than the modern spatial slope. It was argued that using the spatial slope for the interpretation of the ice core data may therefore lead to an underestimation of past temperature during warmer-than-present interglacials (Sime et al., 2008, 2009b).

\subsection{Glaciological contexts}

When drilling sites are located on modern domes, the ice at depth is provided from the same geographical origin as today and the ice flow mostly results from vertical thinning if the domes have stayed at the same locations. Recent studies conducted for EDC and TALDICE suggest that respective changes in advection and accumulation can induce local spatial and temporal accumulation changes and induce migration of dome summits, even at decadal to centennial scale (Urbini et al., 2008). At Vostok and EDML, located on ice ridges, ice core records are formed upstream and transported downward towards the drilling site by ice flow, which requires corrections for upstream effects (due to spatial gradients in accumulation or surface snow isotopic composition) to be applied to these ice core records.

On the central Antarctic Plateau, changes in elevation are expected to be primarily driven by changes in accumulation. Glaciological dating of deep ice cores relies on the assumption of an exponential relationship between water stable isotopes and accumulation rate (due to the temperature dependence of saturation vapor pressure) (Parrenin et al., 2007a). In the EDC3 age scale, modeled accumulation rates are 50 to $20 \%$ higher in the early-late LIG compared to the late Holocene. Higher LIG accumulation rates seem supported by ice core chemistry data (Wolff et al., 2010). Ice core data clearly show that the interglacial accumulation rates are at least twice as high as the glacial accumulation rates (Udisti et al., 2004). As a result of this accumulation effect, the central Antarctic Plateau gradually rises over the course of interglacials. Glaciological models suggest rather similar elevation histories at EDC, Vostok or DF locations, within a few tens of meters (Pollard and DeConto, 2009) (Fig. 7b), also consistent with homogeneous changes in East Antarctic plateau accumulation rates simulated by climate models (Sime et al., 2008, 2009b).

By contrast, the ice flow is more complex near TALDICE. The ice can flow on two sides of TALDICE, either through the small outlets located in the Transantarctic Mountains, or through Wilkes Land, near an efficient ice stream. At this place, shifts in the grounding line - linked with the local sea level - affect upstream ice thickness. During the last glacial period, changes in ice flow induced a $\sim 170 \mathrm{~m}$ thicker ice sheet near TALDICE. Together with the increase of accumulation during the deglaciation, this feature is expected 
to result in a $\sim 100 \pm 50 \mathrm{~m}$ higher elevation at the early Holocene, reaching present day values around $7 \mathrm{kyr}$ (Stenni et al., 2011). It is not expected that MIS5.5 sea level high stand would affect ice flow, as it would only induce a small retreat of the grounding line. Changes in TALDICE elevation are therefore expected to be rather smooth (typically tens of meters per millennium). However, they remain difficult to simulate with ice sheet models which cannot capture realistically the Mountain Transantarctic ice flow and fail to capture the right location of the dome.

Ignoring flow effects and assuming that elevation changes would be purely driven by accumulation, the present day differences in accumulation between the different sites (Table 1) could account for elevation differences between Vostok, EDC and DF by a few meters/millennium, and, for EDML or TALDICE, $40-60 \mathrm{~m}$ per millennium with respect to the three central Plateau sites.

Differences in ice core records may provide constraints on past relative elevation changes. The spatial Antarctic surface air temperature - elevation slope is larger than the dry adiabatic lapse rate, reaching respectively $-11.3,-11.6$ and $-11.9^{\circ} \mathrm{C}$ per $1000 \mathrm{~m}$ for our drilling locations (without TD) $\left(n=5, R^{2}=0.91\right)$, for the whole Antarctic database $\left(n=1280, R^{2}=0.81\right)$, and for the subset of sites located above $2000 \mathrm{~m}\left(n=587, R^{2}=0.61\right)$ (Masson-Delmotte et al., 2008). Sensitivity studies conducted with climate models can be used to estimate the local impact of changes in ice sheet topography. Using the LMDZ model, LGM simulations were run with different estimates of glacial Antarctic topography, leading to different elevations at EDC and EDML of 250 and $200 \mathrm{~m}$, respectively. The simulated "temporal" slopes are respectively of -14.5 and $-10.8^{\circ} \mathrm{C}$ per $1000 \mathrm{~m}$ (Masson-Delmotte et al., 2010b). In previous ice core works, a correction of $9^{\circ} \mathrm{C}$ per $1000 \mathrm{~m}$ was used for correcting past temperatures from changes in EDC elevation (Jouzel et al., 2007). The spatial relationships between elevation and $\delta D$ (resp. $\delta^{18} \mathrm{O}$ ) are $-7.4 \%$ o per $100 \mathrm{~m}, R^{2}=0.74(-0.93 \%$ o per $\left.100 \mathrm{~m}, R^{2}=0.75\right)$ for the whole modern database $(n=1280)$, and appear enhanced above $2000 \mathrm{~m}$ to $-8.0 \%$ per $100 \mathrm{~m}$, $R^{2}=0.56\left(-1.13 \%\right.$ o per $\left.100 \mathrm{~m}, R^{2}=0.64\right)(n=587)$, possibly because of the stronger thermal inversion. Stable isotope - elevation relationships will be used in Sect. 5 for the interpretation of anomalies among the deep ice core stable isotope records, and for comparison with elevation changes simulated by ice sheet models.

\section{Data}

For all the ice cores, isotopic measurements were conducted on successive thin pieces of ice (with lengths varying here between 0.1 and $5 \mathrm{~m}$ ), producing continuous records albeit with different temporal resolutions. Temporal resolution can be enhanced by conducting isotopic measurements at higher depth resolutions but it is limited by wind scouring mixing the initial snow layers and by firn and ice diffusion processes as clearly demonstrated for the deepest part of the EDC ice core (Pol et al., 2011). Based on an intensive study of stake array data, pits and shallow cores at Vostok, Ekaykin et al. (2004) showed that, in central Antarctica, it is possible to resolve $\sim$ decadal variability using stable isotope records.

\subsection{Isotopic records: resolution and age scales}

Vostok: $\delta^{18} \mathrm{O}$ and $\delta \mathrm{D}$ were available from a shallow core (138 m, BH8, with a sampling resolution of $5 \mathrm{~m}$ ) and deep ice cores with a sampling resolution of $5 \mathrm{~m}$ (down to $2083 \mathrm{~m}$ ) and $1 \mathrm{~m}$ (below $2083 \mathrm{~m}$ ). Data were measured at LSCE with an accuracy of $\pm 0.5 \%$ o for $\delta \mathrm{D}, \pm 0.05 \%$ o for $\delta^{18} \mathrm{O}$ data down to $1413 \mathrm{~m}$ and below $2083 \mathrm{~m}$, and $\pm 0.1 \%$ o between 1413 and $2083 \mathrm{~m}$ (Vimeux et al., 1999, 2001b). Several glaciological age scales have been released for Vostok (Petit et al., 1999; Parrenin et al., 2001; Salamatin et al., 2009). On the initial GT4 age scale, the temporal resolution of the data is $220 \pm 50$ years $\left(\delta \mathrm{D}\right.$ and $\left.\delta^{18} \mathrm{O}\right)$ and $22 \pm 5$ years $(\mathrm{BH} 8 \delta \mathrm{D})$ for the Holocene and $290 \pm 70$ years for the last interglacial; here, the error bar is not related to the dating uncertainty but to the variability of the temporal resolution over the periods of interest (linked with the ice core sampling). We have used the published synchronisation of the Vostok ice core records on the EDC3 age scale (Parrenin et al., 2007a).

$E D C: \delta^{18} \mathrm{O}$ and $\delta \mathrm{D}$ were available on the EDC96 core (Holocene) (Jouzel et al., 2001; Stenni et al., 2001) and the EDC99 core (last interglacial) (Jouzel et al., 2007; Stenni et al., 2010a) with a depth resolution of $55 \mathrm{~cm}$. $\delta \mathrm{D}$ data were measured at LSCE with an accuracy of $\pm 0.5 \%$ and $\delta^{18} \mathrm{O}$ data in Trieste and Parma Universities with an accuracy of $\pm 0.05 \%$ o. With the EDC 3 timescale (Parrenin et al., 2007a), this corresponds to a time step of $18 \pm 3$ years for the Holocene and $40 \pm 4$ years for the last interglacial. Changes in local elevation changes were estimated from the glaciological model and used to correct the temperature reconstructions. A slightly modified age scale spanning the Holocene and late glacial has been produced (Lemieux-Dudon et al., 2010) by improved synchronisation of Antarctic and Greenland records.

$E D M L: \delta^{18} \mathrm{O}$ and $\delta \mathrm{D}$ were available with a depth resolution of $50 \mathrm{~cm}$ (EPICA-community-members, 2006; Stenni et al., 2010b) and were measured by Alfred Wegener Institute for Polar and Marine Research (AWI). $\delta \mathrm{D}$ data were measured with an accuracy $\pm 0.5 \%$ and $\delta^{18} \mathrm{O}$ data with an accuracy of $\pm 0.05 \%$. Data were not available from the main core for the upper part (first $113 \mathrm{~m}$ corresponding to the past $1.2 \mathrm{ka}$ ) and the gap was filled using the nearby $148.84 \mathrm{~m}$ deep B32 shallow ice core, sampled on a depth step of $6.2 \pm 1.4 \mathrm{~cm}$ and spanning years $167 \mathrm{AD}-1997 \mathrm{AD}$. A systematic $0.23 \%$ offset was identified from the overlapping period between B32 and EDML main core (1.2-1.6 kyr) and corrected before stacking the data. As the drilling site is not located on a dome, upstream corrections had to be 
performed to account for spatial gradients in surface conditions (EPICA-community-members, 2006). The EDML1 age scale (Ruth et al., 2007) was built to be coherent with EDC3 through volcanic and gas tie points and the synchronisation was recently updated (Lemieux-Dudon et al., 2010). The depth sampling translates into a temporal resolution of $0.8 \pm 0.2$ years for the past $1.2 \mathrm{ka}, 9 \pm 2$ years for the Holocene (1.2 to $12.2 \mathrm{kyr}$ ) and $85 \pm 25$ years for the last interglacial (118 to $131 \mathrm{kyr})$.

$D F: \delta^{18} \mathrm{O}$ data were available from the DF1 ice core with a depth resolution varying between 0.05 and $0.6 \mathrm{~m}$. For the Holocene, the mean depth sampling was $0.27 \pm 0.16 \mathrm{~m}$, and it is systematically $0.5 \mathrm{~m}$ for the last interglacial. Two age scales were available for DF, a glaciological age scale (Watanabe et al., 2003; Parrenin et al., 2007b) and an orbitally tuned age scale (Kawamura et al., 2007). On this orbital DFO-2006 age scale, the temporal resolution of the data is $9 \pm 6$ years for the Holocene and $44 \pm 8$ years for the last interglacial. DF was also placed on EDC3 age scale by peak-to-peak synchronisation of isotopic records, assuming synchronous Antarctic Isotopic Maxima and transitions.

$T D: \delta^{18} \mathrm{O}$ data were available on a $\sim 0.15 \mathrm{~m}$ step for the current interglacial and $\sim 0.22 \mathrm{~m}$ step for the last interglacial (Table 2). The original TD age scale (Steig et al., 1998) has been questioned for the last termination. The synchronisation of calcium (dust) records from TD and EDC has shown that the accumulation rate originally used for the TD age scale was overestimated between 14.5 and $17.5 \mathrm{kyr}$, with implications for the modelling of gas age-ice age differences (Mulvaney et al., 2000; Stenni et al., 2011). It was suggested that very low glacial accumulation rates were caused by enhanced wind scouring. This was confirmed by ice annual layer thickness radar measurements combined with ice flow modelling, and ${ }^{10} \mathrm{Be}$ concentrations (Morse et al., 2007) . The last interglacial record has been tied to the Vostok GT4 age scale based on similarities in the stable isotope records. A synchronisation with GICC05 and EDC3 is not yet available. With the original age scale, the temporal resolution of the data was around $5 \pm 5$ years for the current interglacial but $750 \pm 480$ years for the last interglacial, which is compressed within only $5 \mathrm{~m}$ of ice. We do not have sufficient constraints to produce new age scales for TD. Because of the very low resolution for the last interglacial and the age scale uncertainties, we have decided to display TD data in Fig. 4a and discuss the general structure of the present and last interglacial in this record but could not include this ice core record in subsequent analyses of common variance.

TALDICE: $\delta^{18} \mathrm{O}$ data were available on a $1 \mathrm{~m}$ depth step (Stenni et al., 2011). A glaciological age scale model specific to TALDICE has been developed by methane synchronisation with GICC05 (Buiron et al., 2011; Stenni et al., 2011). For the last interglacial, we used a preliminary age scale established using methane tie points with EDC3 and inverse modelling as described in (Lemieux-Dudon et al., 2010). The available $1 \mathrm{~m}$ record corresponds to a Holocene temporal resolution of $18 \pm 7$ years and a last interglacial temporal resolution of $490 \pm 100$ years. In order to improve the temporal resolution, 980 additional measurements were conducted for Termination II and the last interglacial on a $5 \mathrm{~cm}$ depth step (from $\sim 146$ to $\sim 116 \mathrm{kyr}$ ). The TALDICE age scale was then extrapolated at this depth scale. The new temporal resolution for the last Iinterglacial is therefore $25 \pm 8$ years.

In summary, the records offer temporal resolutions ranging from $\sim 10$ (EDML, DF) to $\sim 30$ years (Vostok, TALDICE, EDC) for the Holocene, and 20 (TALDICE) to $\sim 300$ years (Vostok) for the last interglacial. For the sake of comparisons between records and between the Holocene and last interglacial, we choose to focus on the long-term trends and therefore select a 200 year time step to re-sample all the records (Fig. 4a).

While Greenland Holocene ice cores can be accurately dated using layer counting methods (Vinther et al., 2006), this is not the case for dry central Antarctica where wind scouring and diffusion erase seasonal signals. The dating of the Antarctic Holocene records relies on glaciological and accumulation modelling, together with absolute or relative age markers such as volcanic horizons, gas synchronisation with Greenland records, and alignment of ${ }^{10} \mathrm{Be}$ variations with ${ }^{14} \mathrm{C}$ cosmogenic isotope variations (Parrenin et al., 2007a; Lemieux-Dudon et al., 2010). Altogether, the age scale of Antarctic records for the Holocene is estimated to be associated with a maximum uncertainty of $\sim 200$ years (Lemieux-Dudon et al., 2010). For this reason, assessing the consistency of central Antarctic records on centennial or shorter time scales is out of reach, and we focus on multicentennial and longer term trends.

The uncertainty linked with the last interglacial absolute age is estimated to be $\sim 3 \mathrm{ka}$, and the uncertainty on its duration about 20\% (Parrenin et al., 2007a; Kawamura et al., 2007). The EDC3 age scale has recently been supported by the absolute dating of Mount Moulton tephra (Dunbar et al., 2008; Popp et al., 2004). We have therefore chosen to use all the other records (Vostok and DF) on the EDC3 age scale. This synchronisation lies on volcanic, methane and dust tie points (EDML, TALDICE) for the Holocene and the last deglaciation. For the previous interglacial, it mostly relies on the hypothesis of synchronous climate and water stable isotope fluctuations. Marino et al. (2009) recently demonstrated coherent geochemical dust composition at EDML and EDC, confirming earlier results obtained at Vostok and EDC and showing a common southern South American provenance of glacial dust to East Antarctica. The available dust data clearly confirm the synchronism of Eastern Antarctic stable isotope variations. 

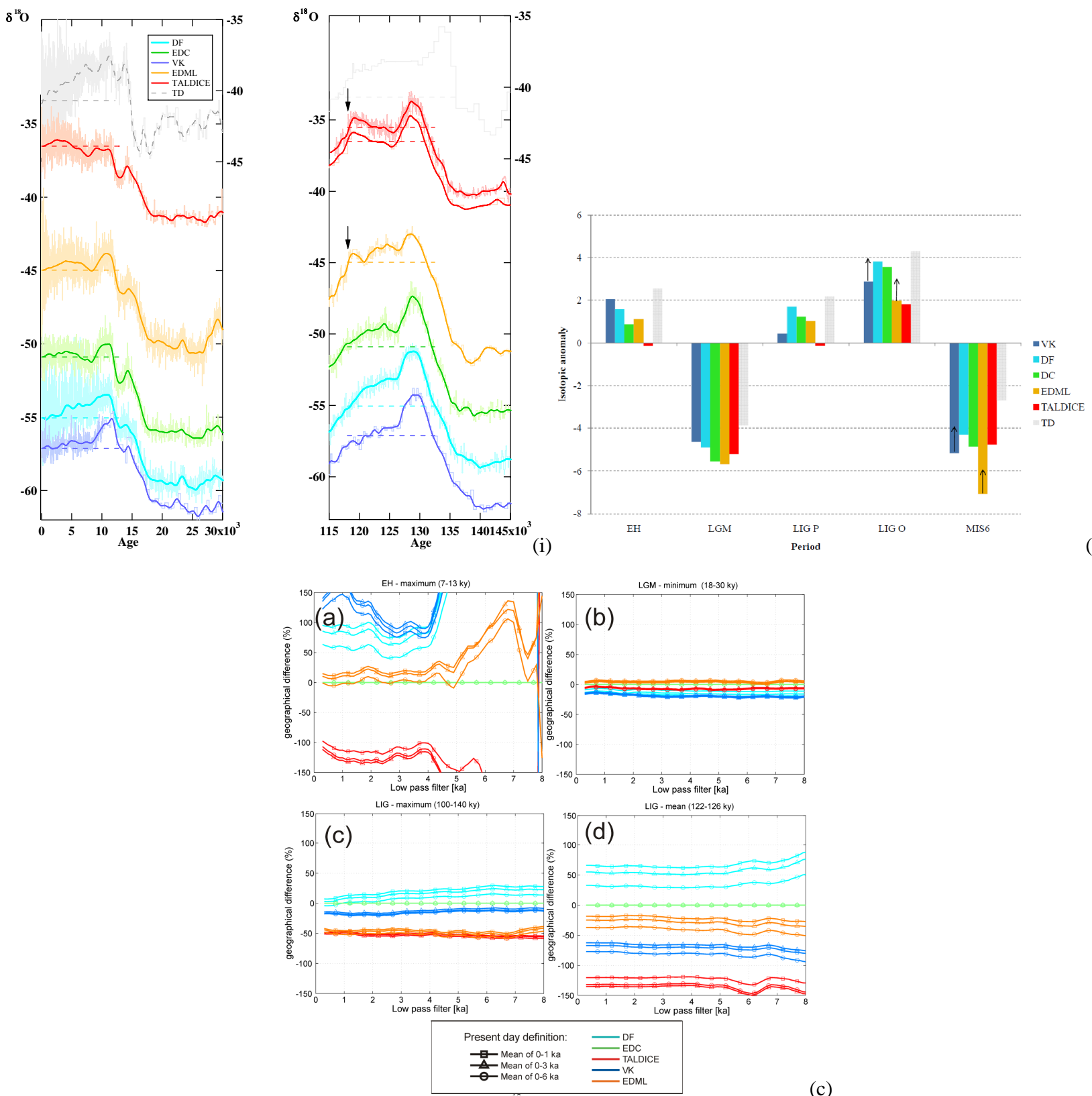

(c)

Fig. 4. (i) Original water stable isotope records available from all ice core sites (\%), displayed on the EDC3 age scale for the current (left panel) and last (right panel) interglacial periods with the exception of TD on its initial age scale (grey, left vertical axis with the same vertical scaling as for the right axis). All raw data (thin lines) and 5 point binomial filter 200 year re-sampled data are displayed (bold lines). Two series of measurements are available for the last interglacial period for TALDICE: bag samples $(1 \mathrm{~m})$ and fine samples $(0.05 \mathrm{~m})$. The high resolution data have been artificially shifted by $1 \%$ for readability. The black arrows display the abrupt TALDICE and EDML $\delta^{18} \mathrm{O}$ decrease observed at $\sim 118$ kyr. (ii) Based on the smoothed records displayed in Fig. 4a, comparison of the $\delta^{18} \mathrm{O}$ anomalies (\%o between the last millennium (reference), the early Holocene EH (warmest millennium between 7 and $13 \mathrm{kyr}$ ), the Last Glacial Maximum LGM (coldest millennium between 18 and $30 \mathrm{kyr}$ ), the optimum of the last interglacial (LIG) $\mathrm{O}$ (warmest millennium between 100 and $140 \mathrm{kyr}$ ), the plateau of the last interglacial LIG P (mean conditions between 122 and $126 \mathrm{kyr}$ ) and the previous glacial maximum MIS6 (coldest millennium between 130 and $150 \mathrm{kyr}$ ). The Vostok and EDML records are affected by changes in upstream ice origin leading to a decreasing $\delta^{18} \mathrm{O}$ trend clearly visible for LIG O and MIS6. The published estimates for the upstream effects are displayed as vertical arrows, (without taking into account changes in ice sheet elevation with time). The same analyses were conducted on TD despite chronological uncertainties (grey bars). (iii) Sensitivity analysis of the $\delta^{18} \mathrm{O}$ geographical anomalies: tests conducted with respect to the definition of the "present-day" $(0-$ $1 \mathrm{kyr}, 0-3 \mathrm{kyr}$ or $0-6 \mathrm{kyr}$ mean, different symbols) and with respect to the smoothing length applied to the data ( 0.2 to $8 \mathrm{ka}$, horizontal axis). Percentage differences are relative to EDC and displayed for each time interval - (a) Early Holocene, (b) LGM, (c) LIG maximum and (d) LIG mean. For clarity, different y-axis scales are used for the different panels. Note that the Vostok and EDML record are affected by changes in upstream ice origin leading to a decreasing $\delta^{18} \mathrm{O}$ trend for the oldest time periods. 


\subsection{Sea water and glaciological corrections}

\section{Sea water isotopic composition}

Ice core $\delta^{18} \mathrm{O}$ data incorporate a signature of changes in sea water $\delta^{18} \mathrm{O}_{\mathrm{sw}}$, which varies during glacial-interglacial periods due to changes in ice volume. Classically, $\delta^{18} \mathrm{O}_{\mathrm{sw}}$ is extracted from paleoceanography data (Bintanja et al., 2005) and synchronised on ice core age scales such as EDC3 (Parrenin et al., 2007a). $\delta^{18} \mathrm{O}_{\mathrm{sw}}$ affects the initial water vapour isotopic composition and this initial anomaly is altered during distillation, leading to a final imprint $\delta^{18} \mathrm{O}$ on ice core $\delta^{18} \mathrm{O}$ which is expressed by:

$\Delta^{18} \mathrm{O}_{\text {corr }}=\Delta^{18} \mathrm{O}_{\mathrm{sw}} \frac{\left(1+\frac{\Delta^{18} \mathrm{O}_{\text {ice }}}{1000}\right)}{\left(1+\frac{\Delta^{18} \mathrm{O}_{\mathrm{sw}}}{1000}\right)}$

Over the last $150 \mathrm{ka}$, our five ice cores have displayed $\delta^{18} \mathrm{O}$ values ranging between -62 and $-33 \%$, leading to minor $(\sim 0.03 \%$ o $)$ differences in the classical sea water correction applied to the different sites. This factor cannot explain any significant differences between sites.

\section{Glaciological corrections}

VOSTOK: The ice below Vostok has been transported from its surface upstream origin, towards Ridge B. Vimeux et al. (2001a) indeed showed a marked change in Vostok deuterium excess prior to $250 \mathrm{kyr}$ (at depths lower than $2820 \mathrm{~m}$ ), corresponding to a surface ice origin $230 \mathrm{~km}$ from Vostok. Holocene ice was deposited 0-30 km from Vostok, while last interglacial ice originates in an area located $110-130 \mathrm{~km}$ further in the direction of Ridge B. Changes in accumulation gradients were discussed by Parrenin et al. (2004) and used for improving the Vostok glaciological age scale. Based on a linear interpolation of the modern spatial $\delta^{18} \mathrm{O}$ gradient between Vostok and Dome B (2\%o over $280 \mathrm{~km})$, an initial deposition site $130 \mathrm{~km}$ upstream of Vostok is expected to induce a progressive glaciological $\delta^{18} \mathrm{O}$ depletion reaching $\sim 1 \%$ o during the last interglacial. However, glaciological investigations carried out in the interval 0-110 km from Vostok towards Ridge B along the flow line showed no significant trend in surface snow $\delta^{18} \mathrm{O}$ content (Ekaykin et al., 2010), thus no correction was performed on stable isotope records. Vostok ice core total air content data (V. Lipenkov, personal communication, 2010 ) are coherent with an $\sim 80$ m lower initial surface elevation during glacial maxima than at present day.

EDML: Using a glaciological model forced by temperature and accumulation derived from ice core data, Huybrechts et al. (2007) simulated the EDML elevation history and the upstream origin of EDML ice, expressed in elevation as well. The change in elevation of the surface ice was then used to correct EDML $\delta^{18} \mathrm{O}$ using the present day local isotope-elevation slope $(-0.96 \%$ o per $100 \mathrm{~m})$. Upstream of EDML, the ice sheet surface is expected to be higher during glacial periods and lower during interglacial periods in response to changes in ice flow. The elevation effect is modelled to vary between -50 and $-125 \mathrm{~m}$ during the last interglacial; the upstream origin effect is expected to add -190 to $-220 \mathrm{~m}$ for the same time interval. Altogether, the glaciological effects are simulated to induce an elevation effect between -250 and $-335 \mathrm{~m}$ from 120 to $130 \mathrm{kyr}$, corresponding to a $\delta^{18} \mathrm{O}$ "glaciological" depletion of 2.4 to $3.2 \%$, going back to $\sim 1.2 \%$ o during MIS6 (because of a higher glacial elevation in this area). In the next sections, raw data have been used because of uncertainties on glaciological corrections (Stenni et al., 2010b).

EDC: A sub-product of the 1-D glaciological modelling (Parrenin et al., 2007b) is the reconstruction of local ice thickness, mainly responding to accumulation changes. This was used by Jouzel et al. (2007) to correct EDC temperature reconstructions. For EDC, a comparison of existing glaciological simulations (Huybrechts et al., 2007; Parrenin et al., 2007b; Pollard and DeConto, 2009) (Fig. 7) shows comparable orders of magnitude, typically $\sim 100 \mathrm{~m}$ at the glacialinterglacial scale, but strong differences over the course of the last interglacial. While elevation corrections remain secondary at the glacial-interglacial scale (about $10 \%$ of the temperature amplitude), within an interglacial period they can reach amplitudes comparable to temperature trends derived from stable isotope data $\left(\sim 1^{\circ} \mathrm{C}\right)$.

Changes in Antarctic elevation have also been extracted for Vostok, Dome F, EDML, and EDC from a long 3-D ice sheet simulation (Pollard and DeConto, 2009) forced by marine data. This simulation did not use ice core data, thus ignoring the impact of local accumulation or temperature changes - which are however expected to be rather homogeneous on the East Antarctic plateau as discussed previously. This has produced rather homogeneous elevation changes at Vostok, EDC, and DF (Fig. 7c and d).

\subsection{Comparison between the different ice core records}

All records (Fig. 4a and b) depict comparable glacial (LGM) to present-day (last millennium) $\delta^{18} \mathrm{O}$ increase, with a mean amplitude of $\sim 5.2 \%$ and an inter-site standard deviation of $0.4 \%$. In this section, we will refer to differences between a given past period and present day (average values over the last millennium) as "anomalies". We note that these results are sensitive to the prescribed definition of "the present-day" and also to the data filtering applied. We explore both of these aspects in Sect. 4.4 and Fig. 4c.

All sites exhibit an early Holocene maximum between $\sim 12$ and $9 \mathrm{kyr}$, albeit with different amplitudes: while it reaches an anomaly of $\sim 2 \%$ above present-day at Vostok, this anomaly is only $\sim 1.6 \%$ at DF, $\sim 1.1 \%$ at EDML and $0.9 \% \circ$ at EDC. At TALDICE, early Holocene levels even stay below present-day levels. After this optimum, Vostok and DF exhibit a decreasing trend towards present-day 
values, while EDC, EDML and TALDICE exhibit a midHolocene secondary maximum, most strongly imprinted in TALDICE. There are therefore strong differences in glacialinterglacial amplitudes if one considers the reference period as the last millennium or the early Holocene. The most depleted sites (Vostok and DF) exhibit the weakest glacialpresent day magnitude, but strongest early Holocene optimum magnitude. This points to either different amplitudes of temperature changes or different isotope-temperature relationships in the different Antarctic sectors (Vostok and DF being more coherent than EDC and EDML). The Holocene $\delta^{18} \mathrm{O}$ at TALDICE appears as an exception which could arise from changes in local elevation and/or in moisture source and pathways linked to the open Ross Sea during deglaciation (Fig. 4).

The magnitude of MIS6 $\delta^{18} \mathrm{O}$ anomaly differs more strongly between sites than for the LGM, plausibly as a consequence of upstream ice origin at EDML and Vostok imposing stronger depletion. At DC and DF, MIS6 appears $0.6-0.7 \%$ less depleted than the LGM (around $25 \mathrm{kyr}$ ). Assuming that the reference sites are DC and DF, this would suggest an upstream effect reaching $-0.5 \%$ at Vostok and $-2.5 \%$ at EDML, compatible with glaciological constraints suggesting EDML upstream and elevation effects of $\sim 300 \mathrm{~m}$ (Fig. 4).

The early optimum of the LIG appears systematically stronger than the early Holocene maximum, leading to larger deglacial amplitude (between the glacial minimum and the interglacial maximum levels) during Termination II than during Termination I; this amplification varies from $20 \%$ (Vostok) to $32 \%$ (EDML). The LIG optimum anomaly (with respect to present day) is strongest at DF (3.8\%), DC $(3.5 \%)$, and Vostok $(2.8 \%)$, followed by EDML $(2.0 \%)$ and TALDICE $(1.8 \%$ ) .

Interestingly, the initial isotopic profiles (Fig. 4) also highlight two abrupt decreases in the isotopic values at TALDICE and EDML, around $118.5 \mathrm{kyr}$ (black vertical arrows on Fig. 4). These two rapid drops were not recorded at the more inland sites (DF, EDC and Vostok). It is unlikely that both result synchronously from an abrupt increase in the local ice sheet topography, by about $200 \mathrm{~m}$ within $<400 \mathrm{yr}$, in two different areas. It is likely that such a fast isotopic decrease at the two sites most sensitive under interglacial conditions to high latitude moisture transport (see Sect. 3) results either from changes in precipitation intermittency or from an abrupt shift of moisture origin. During glacial inception, an increased seasonal ice cover in the Ross Sea/Weddell Sea sector may have closed a previous local moisture source, enlarging the distance between source and site. Such changes in moisture transport could have contributed to a stronger final isotopic depletion. This hypothesis needs further investigation, for instance using proxies of moisture origin (e.g. deuterium and oxygen 17 excess) and of regional sea ice potentially available from marine records or ice core aerosols.

\subsection{Sensitivity study of the inter-site differences}

The simple comparison discussed in the previous section highlights inter-site differences and suggests that they may differ from one warm interval to the next. Here, we have assessed the robustness of these inter-site $\delta^{18} \mathrm{O}$ differences (Fig. 4b). For this purpose, we quantified the sensitivity of the $\delta^{18} \mathrm{O}$ anomaly analysis examining the results for the same past periods, except for the older MIS6 glacial maximum which is not sufficiently resolved in the available TALDICE and EDML records.

The sensitivity check has been carried out with respect to (i) the smoothing of the data, and (ii) the reference "presentday" period. First, for each event, and for each ice core, we calculated a mean value for a given past period (as defined in Fig. 4b, e.g. the Early Holocene $\delta^{18} \mathrm{O}$ maximum between $7-13 \mathrm{kyr}$ ). We repeated this analysis, using progressively more strongly smoothed (low-pass filtered) $\delta^{18} \mathrm{O}$ time series. The low-pass filtering was carried out over a large range of values between 0.2 and $8 \mathrm{kyr}$, using $0.2 \mathrm{ka}$ filtering intervals. This provides forty sets of values, for each ice core and for each past period, calculated using gradually more strongly smoothed time-series. Secondly, we calculated "present-day" mean values for each ice core site using three alternative specifications. These specifications are: a last millennium mean (0-1 kyr mean); a late Holocene mean (0-3 kyr mean); and a mid-Holocene mean (0-6 kyr mean).

For each ice core-site, each of the forty past period mean values was subtracted from each of these three "present-day" reference values. This has given 120 possible anomaly values for each core site and each period, providing a relatively complete depiction of the dependency of Fig. $4 b$ on the data smoothing and the specification of "present-day". Figure 4c depicts these sensitivity test results. The results are presented as "geographical percentage differences", calculated as the ratio between the individual ice core anomaly and the EDC ice core anomaly. We used EDC as a reference because it appears to have an "average" behaviour in Fig. $4 \mathrm{~b}$ and because it has been drilled on a central East Antarctic plateau dome (with therefore minimal glaciological biases).

A percentage difference of $0 \%$ means that the individual site period anomaly is equal to the EDC anomaly, and therefore shows that there is no geographical difference between the anomaly at this ice-core site and at EDC. A difference of $100 \%$ would mean that the ice core site anomaly is twice as large as the EDC anomaly, indicating a large geographical difference.

The results are displayed in Fig. 4 as a function of the smoothing length. They depict robust similarities between the geographical anomalies of the EH and LIG, with the exception of the Vostok and EDML sites (which are likely affected by a negative glaciological bias, see Sect. 4.2). DF appears to have generally $\sim 60 \%$ larger anomalies than EDC, and TALDICE systematically -120 to $-150 \%$ anomalies. Our sensitivity study shows that the geographical percentage 
differences vary a lot for the EH depending on the filtering length, especially above $4 \mathrm{ka}$. For earlier periods, results are not very sensitive to the choice of the smoothing length (Fig. 4). The geographical percentage differences are affected (up to $50 \%$ ) by the choice of the reference period (e.g. $0-1,0-3$ or $0-6$ kyr mean).

Our sensitivity tests show that the analysis of the "peak" $\delta^{18} \mathrm{O}$ anomaly values can be sensitive to data smoothing and to the specification of "present-day". An alternative "relative rate of change" approach for examining geographical patterns, was outlined in Sime et al. (2009b). This method can alleviate the problems linked with glaciological trends and may be worthwhile pursuing in the future.

The inter-site comparison is indeed complicated by glaciological biases for non-dome sites such as Vostok and EDML. The analysis confirms that there are systematic differences between EDC and DF East Antarctic Plateau sites, with a stronger isotopic anomaly at DF than at EDC during warm periods. With this type of analysis, we cannot reach a definitive conclusion about the stability of the VK or EDML patterns between the different warm periods, due to glaciological effects. Our analysis nevertheless suggests that EDC, DF, and probably VK (if corrected for glaciological trends) $\delta^{18} \mathrm{O}$ follow a similar geographical pattern of EH and LIG anomalies on the high East Antarctic Plateau. We note the complex structure of EDML anomalies, which may display different patterns of warm period isotopic responses during the $\mathrm{EH}$ and LIG (Fig. 4a-c). Finally, the specificity of TALDICE is confirmed, with a distinct site-specific pattern robust between EH and LIG.

\section{Analysis of the inter-site differences}

The previous section clearly evidences that there are both common signals and local specificities in the ice core records of the present and last interglacials. This section is dedicated to the analysis of the inter-site differences. We first specify the problems arising from changes in isotope-temperature relationships (Sect. 5.1), and analyse the potential contribution of changes in moisture source to regional anomalies, thanks to corrections using deuterium excess measurements (Sect. 5.2). We then quantify the isotopic signal common to the five high-resolution records using principal component analyses (Sect. 5.3). We finally quantify elevation changes which could account for local differences, and compare them with ice sheet model results (Sect. 5.4).

\subsection{Interpretation of isotopic deviations}

For each of our ice core sites $(i)$, and for each time period $(t)$, we have access to the local and instantaneous ice core isotopic composition $\delta^{18} \mathrm{O}_{i, t}$. Changes in $\delta^{18} \mathrm{O}_{i, t}$ are expected to depend on local temperature $T_{i, t \mid z_{0}}$ "at fixed elevation" but also on local elevation changes $z_{i, t}$ :

$\delta^{18} \mathrm{O}_{i, t}=\alpha_{i, t} T_{i, t \mid z_{0}}+\beta_{i, t} z_{i, t}$

Equation (1) relates $\delta^{18} \mathrm{O}_{i, t}$ to changes in local air temperature through a "temporal slope" $\alpha_{i, t}$ varying with site $(i)$ and time $(t)$. The modern Antarctic spatial slope is well established from a database of modern snowfall and surface snow isotopic composition, with an average Antarctic slope of $0.8 \%$ per ${ }^{\circ} \mathrm{C}$ (Masson-Delmotte et al., 2008). This isotopetemperature coefficient hides a variety of factors that add to the well known Raleigh distillation effect, such as intermittency/ seasonality of snowfall, inversion strength, moisture source effects and advection history (see Sect. 3).

Until recently, Antarctic temperature reconstructions have assumed a linear and temporally constant $\alpha_{i, t}$, on the glacialpresent-day scale, a hypothesis supported by glacial climate simulations conducted with isotopic atmospheric general circulation models (Jouzel et al., 2007; Sime et al., 2009b). This implies that anomalies in $\delta^{18} \mathrm{O}_{i, t}$ are expected to mainly depend on anomalies in local temperature and/or elevation. However, modelling studies conducted under projected increased atmospheric $\mathrm{CO}_{2}$ concentrations (Sime et al., 2008) have recently questioned whether the single linear $\alpha_{i, t}$ hypothesis holds for climates warmer than present day, and suggested temporally and spatially varying $\alpha_{i, t}$. An analysis of the relative rates of changes of $\delta^{18} \mathrm{O}_{i, t}$ between Vostok, EDC and DF alongside with isotope-enabled model outputs has been used to suggest a rather small $\alpha_{\mathrm{DF}}$ but a climatically variable $\alpha_{\mathrm{EDV}, t}$ (Sime et al., 2009b) for Vostok and EDC.

Due to the lack of independent temperature and elevation constraints, Eq. (1) is under-constrained and cannot be solved. Assuming a homogeneous temperature change on the central Antarctic plateau immediately attributes anomalies in $\delta^{18} \mathrm{O}_{i}$ to spatial differences in $\bar{\alpha}_{1}$, defined as the average of $\alpha_{i, t}$ between the periods $t$ and $t_{0}$ :

$\frac{\delta^{18} \mathrm{O}_{i, t}-\delta^{18} \mathrm{O}_{i, t_{0}}}{\delta^{18} \mathrm{O}_{j, t}-\delta^{18} \mathrm{O}_{j, t_{0}}} \sim \frac{\overline{\alpha_{l}}}{\overline{\alpha_{j}}}$

In order to explore these inter-site anomaly ratios, Fig. 4b displays the early Holocene, MIS2, MIS6, LIG optimum and LIG plateau anomalies for DF, TALDICE, Vostok, EDC and EDML. Let us explore if we can identify a constant scaling between the various sites with the example of EDC/DF. The EDC/DF anomaly ratio (as defined in Eq. 2) is slightly higher than 1 during glacial maxima (resp. 1.12 and 1.13 for MIS2 and MIS6), weak during the early Holocene optimum (0.6) and LIG plateau (0.7), and again higher (0.9) during the LIG optimum. Ignoring glaciological effects (e.g. due to local elevation changes) and assuming a homogeneous temperature change at EDC and DF, the data suggest smaller isotope-temperature slopes at EDC compared to DF for periods warmer than today. However, the results do not appear stable over the three warm periods analysed here. The 
processes accounting for changes in the isotope-temperature slope, such as precipitation intermittency of moisture origin effects, may differ between these various warm episodes (EH, LIG plateau, LIG optimum), which have very likely different causes (bipolar seesaw, response to orbital forcing...) (Masson-Delmotte et al., 2010a).

For Vostok and EDML, this comparison does not fully make sense because of uncertain upstream corrections (as indicated by black vertical arrows on Fig. 4b). TALDICE clearly appears as an outlier, with almost no change during the EH or the LIG plateau and a small anomaly during the LIG optimum. TALDICE shows coherent trends and amplitudes during glacial periods with Plateau cores, whereas it exhibits a strong difference during the Early Holocene. This different behaviour is coherent with the sensitivity of the site to ice sheet retreat during the opening of the Ross Sea (Stenni et al., 2011). However, it should be noted that despite its sensitivity to ice sheet retreat, TALDICE is qualitatively coherent with other ice cores at the LIG optimum.

Finally, the TD ice core appears quite peculiar. It exhibits the strongest positive anomalies with respect to the present day levels during the present and last interglacials, but the smallest negative glacial amplitudes. Differences between TD and TALDICE are particularly surprising given the proximity of the drilling sites, but they are consistent with large differences in moisture sources (Sect. 3, Fig. 2). Given earlier findings regarding the possible accumulation hiatus during the last glacial (Morse et al., 1998), for this specific site we cannot rule out that some of the characteristics arise from site-specific precipitation intermittency and/or wind erosion effects.

\subsection{Changes in moisture origin}

The analysis of moisture origin (Sect. 3) has demonstrated regional specificities in the modern seasonal moisture sources. Changes in moisture origin and evaporation conditions are known to affect the initial water vapour isotopic composition, and therefore the isotopic composition of Antarctic snowfall (Dansgaard, 1964). Second order isotopic parameters such as deuterium excess and oxygen 17 excess are more sensitive to evaporation conditions than $\delta \mathrm{D}$ or $\delta^{18} \mathrm{O}$. These supplementary data can provide constraints on changes in moisture origin and correct their impacts of $\delta \mathrm{D}$ or $\delta^{18} \mathrm{O}$. Methodologies have been developed to quantify changes in source and site temperatures. For our sites and periods of interest, estimates of biases linked with changes in moisture sources have been produced using deuterium excess for EDC, EDML, Dome F and Vostok; this is not yet the case for TALDICE and TD.

Figure 5 displays the comparison between the $\delta^{18} \mathrm{O}$ records and these published site temperature reconstructions, which take into account deuterium excess constraints on changes in moisture origin, as well as changes in sea water isotopic composition (see Sect. 3). Based on Rayleigh models, these reconstructions do not take into account precipitation intermittency. Classical temperature reconstructions are linearly related to isotopic records and do not take into account these source effects. The differences between the isotopic records (or the conventional reconstructions) (solid lines, Fig. 5) and the site temperature estimates (dashed lines, Fig. 5) are used here to illustrate the possible magnitude of moisture source biases.

For EDC, the site temperature estimate is up to $\sim 0.5^{\circ} \mathrm{C}$ higher than the conventional temperature reconstruction around 9.5 to $6 \mathrm{ka}$ (Masson-Delmotte et al., 2004). For the last interglacial, the site temperature estimate shows $\sim 0.5^{\circ} \mathrm{C}-1{ }^{\circ} \mathrm{C}$ warmer conditions after the early interglacial optimum, and enhanced by $\sim 1.5^{\circ} \mathrm{C}$, the secondary temperature optimum (Stenni et al., 2010a). For EDML, the site temperature estimate is up to $1^{\circ} \mathrm{C}$ lower than the conventional temperature reconstruction during the Early Holocene optimum, $\sim 0.5^{\circ} \mathrm{C}$ during the secondary last interglacial optimum (Stenni et al., 2010a). At DF, a site temperature estimate has been published (Kawamura et al., 2007) using deuterium excess data (Uemura et al., 2004). The visual comparison between the site temperature and $\delta^{18} \mathrm{O}$ records (from their Fig. 2) shows some differences. During the Holocene, the moisture source correction leads to a $0.5^{\circ} \mathrm{C}$ weaker early Holocene optimum, and removes the $\sim 1{ }^{\circ} \mathrm{C}$ mid to late Holocene decreasing trend derived from $\delta^{18} \mathrm{O}$ data. During the last interglacial, the moisture source correction also slightly lessens the early optimum (by about $0.5^{\circ} \mathrm{C}$ ), produces a secondary temperature optimum of $\sim 2{ }^{\circ} \mathrm{C}$ and delays glacial inception cooling. Surprisingly, DF site temperature shows more similarity with DC temperature or isotopic records than DF and DC isotopic records do.

Vostok site temperature estimates have been published using deuterium excess data (Cuffey and Vimeux, 2001; Vimeux et al., 2002). As for DF, the moisture source correction leads to $\mathrm{a} \sim 1{ }^{\circ} \mathrm{C}$ weaker early Holocene optimum and a reduced late Holocene decreasing trend, a later and slightly weaker early last interglacial optimum and a weaker cooling trend during the last glacial inception. Temperature differences remain within $\sim 1.5^{\circ} \mathrm{C}$.

Inspection of corrections introduced by the use of deuterium excess suggests limited albeit non-negligible influence on interglacial trends. We show that the available information (i) rules out that early interglacial or mid- interglacial maxima and differences between interglacials are artefacts caused by changes in the moisture source; (ii) rules out a dominant contribution of changes in the moisture source on isotopic trends over the course of interglacials. Figure 5 suggests that the relative amplitude of maxima can be affected by moisture source effects, with different amplitudes for the different events and the different sites. This calls for further examination of moisture source impacts on past isotope-temperature changes, using both second order isotope data such as deuterium and oxygen 17 excess, and isotopic atmospheric general circulation models. The caveats of our analysis lie in different quantification methods and 

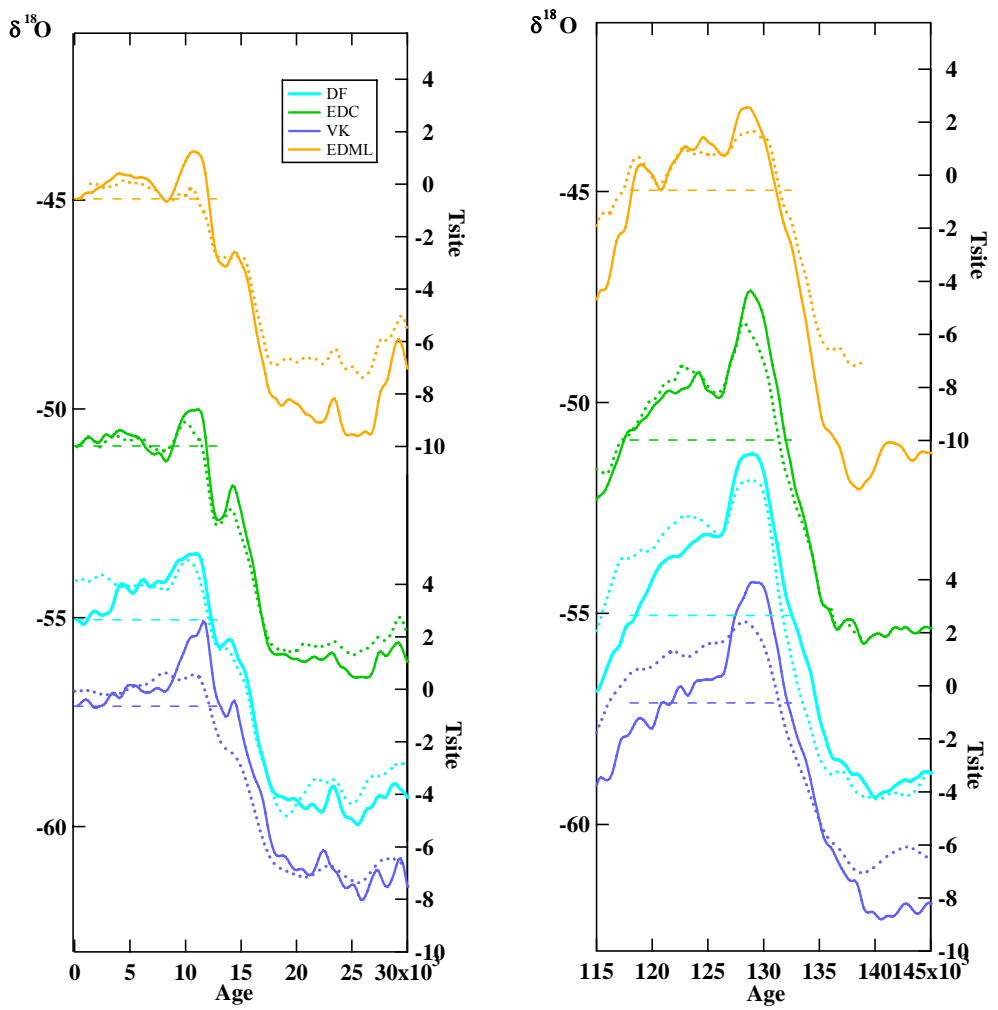

Fig. 5. Comparison between the initial isotopic records (\%o, left axis, bold lines) and the site temperature $\left({ }^{\circ} \mathrm{C}\right.$, right axis, same temperature scaling for all records, dotted lines) estimated after correction for sea water isotopic composition and moisture source correction taking into account deuterium excess data, for EDC and EDML (Stenni et al., 2010b), Vostok (Vimeux et al., 2001a) and Dome F (Uemura et al., 2004; Kawamura et al., 2007). The resolution of the Tsite records varies between 200 years (EDC and EDML), 300 years (DF) and 400 years (Vostok). They have been normalized with respect to the last millennium and smoothed using a binomial filter to highlight only multi-millennial trends. (a) Current interglacial, and (b) last interglacial. With this approach, strong increases in deuterium excess during interglacials at Vostok and DF (not shown here) appear to account for long- term interglacial isotopic decreases.

different temporal resolutions for site temperature reconstructions, and the lack of published deuterium excess information for TALDICE and TD. For this reason, we have not performed the subsequent analyses on the site temperature estimates, but on the $\delta^{18} \mathrm{O}$ records.

\subsection{Principal component analyses}

To explore the reasons for the inter-site differences, one can assume that each site $\delta^{18} \mathrm{O}_{i, t}$ isotopic record is made of a linear combination of a common Antarctic signal $\overline{\delta^{18} \mathrm{O}_{t}}(\mathrm{ex}-$ pected to reflect a "mean Antarctic temperature history") and a local anomaly $\overline{\Delta^{18} \mathrm{O}_{i, t}}$, which can then depend on (1) local elevation, (2) local temperature, (3) isotopic processes linked with moisture origin, transport, and precipitation intermittency, (4) upstream glaciological effects, (5) errors on ice core synchronisation:

$\delta^{18} \mathrm{O}_{i, t}=\overline{\delta^{18} \mathrm{O}_{t}}+\Delta^{18} \mathrm{O}_{i, t}$

In this section, we first describe the extraction of the mean signal, then the local residuals, and discuss the local glaciological or climate-isotopic processes that can be at play. The five $\delta^{18} \mathrm{O}_{i, t}$ records are all placed on a common age scale (here, EDC3) and re-sampled on a common time step of 200 years. These re-sampled data are then smoothed using a 5 point binomial filter. Figure 4 a displays the raw data (light lines) and therefore the differential initial temporal resolution of each time series, together with the smoothed data (bold lines).

In order to extract the common $\overline{\delta^{18} \mathrm{O}_{t}}$ signal, a principal component analysis has been performed on the five smoothed records using Analyseries software (Paillard et al., 1996). For the current interglacial period, the first two EOF calculated on data from 0 to $15 \mathrm{kyr}$ capture respectively $78 \%$ and $18 \%$ of common variance. For the last interglacial period, the first two EOFs calculated on data from 135 to $116 \mathrm{kyr}$ capture $91 \%$ and $5 \%$ of common variance (Table 3, Fig. 6). PC1 is interpreted to reflect the common $\overline{\delta^{18} \mathrm{O}_{t}}$ signal, with $\mathrm{PC} 2$ expressing some of the site-specific differences. The magnitude of variance expressed in PC1 clearly demonstrates homogeneous stable isotope changes in the five East Antarctic records. 


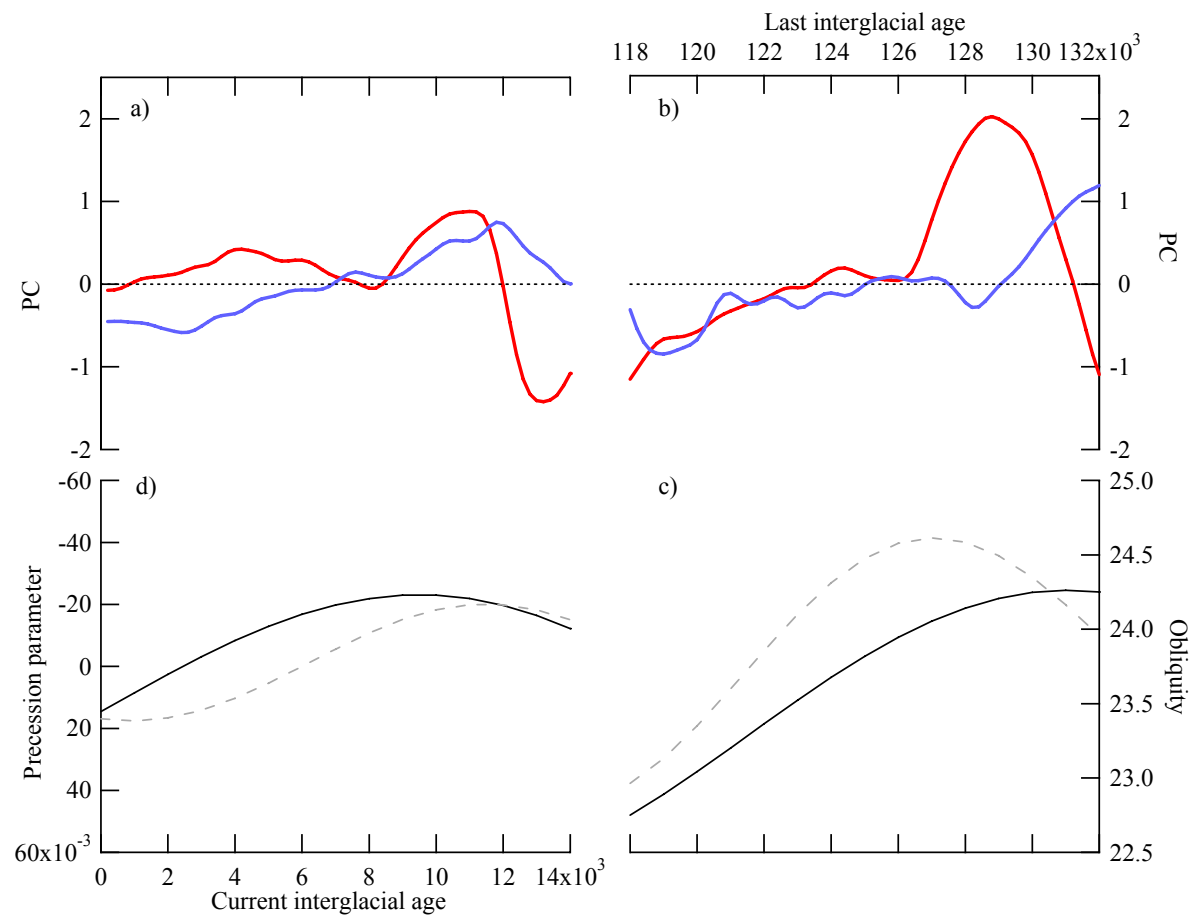

Fig. 6. (a) Common and residual signals highlighted by principal component analyses, showing the first (red) and second (blue) principal components of the $5 \delta^{18} \mathrm{O}$ records (TD not included) together with the percentage of variance explained, for the Holocene (expressed in $\% o$ anomalies). (b) Same as (a) but for the last interglacial. (c) Last interglacial orbital context, as displayed by variations in obliquity (thick black line) and reversed precession parameter (dashed grey line) (Laskar et al., 1993). (d) Same as (c) but for the Holocene.

For the current interglacial period, PC1 shows a $\sim 1 \%$ o early Holocene optimum from 11.5 to $10 \mathrm{kyr}$, followed by a minimum at $8 \mathrm{kyr}$ (comparable to present day) and a secondary maximum reaching $\sim 0.4 \%$ at $4 \mathrm{kyr}$ (Fig. 6). PC2 mostly accounts for a $\sim 1 \%$ o decreasing trend from 12 to 2 kyr. The long term trend seen in PC2 is most likely due to long-term glaciological changes. For the previous interglacial, PC1 peaks at $128.5 \mathrm{kyr}$ with a $\sim 2 \%$ o strong early optimum, followed by a minimum at $126 \mathrm{kyr}$, and a secondary weak maximum $(\sim 0.2 \%$ ) at $124 \mathrm{kyr}$ (difficult to detect from the millennial variability), and a progressive decreasing trend. PC2 appears as a $\sim 2 \%$ o decreasing trend (albeit with different rates of changes over time). We therefore observe rather comparable patterns of changes over the course of the present and last interglacials, with about twice larger magnitude during the last interglacial period in East Antarctica. The larger magnitude of changes during MIS5.5 may be linked with the different orbital contexts (Fig. 6, right panel) marked by a larger eccentricity, stronger variations in the precession parameter, as well as a different phasing between the precession and obliquity extrema than during the Holocene. The links between orbital forcing and Antarctic temperature variations remain elusive, as both local seasonal insolation (Renssen et al., 2004; Timmermann et al., 2009) and Northern Hemisphere insolation (Kawamura et al., 2007) may be at play (e.g. through the impact of Northern
Table 3. Principal component analysis of the five smoothed $\delta^{18} \mathrm{O}$ records for the present and last interglacial periods: percentage of variance explained by the first and second EOF and their sum, and linear coefficients applied to each record. The third EOF accounts for $\sim 2.5 \%$ of variance and is not displayed. TD is not included due to its low resolution and dating accuracy for the last interglacial.

\begin{tabular}{llcrrrr}
\hline Period & \% of variance & DF & EDC & TALDICE & VK & EDML \\
\hline Current & EOF1 78.4\% & 0.44 & 0.50 & 0.44 & 0.26 & 0.54 \\
interglacial & EOF2 $17.8 \%$ & 0.37 & -0.11 & -0.63 & 0.67 & -0.01 \\
& Total: $96.2 \%$ & & & & & \\
\hline Last & EOF1 91.1\% & 0.57 & 0.46 & 0.27 & 0.51 & 0.36 \\
interglacial & EOF2 5.2\% & 0.17 & -0.003 & -0.59 & 0.53 & -0.58 \\
& Total: $96.3 \%$ & & & & & \\
\hline
\end{tabular}

Hemisphere insolation on the deglacial freshwater flux and ocean circulation). With the EDC3 age scale, we can simply rule out a constant phase lag between early interglacial optima and the precession parameter as the MIS5.5 occurs prior to the precession parameter minimum, while the early Holocene occurs later. This finding obtained with the EDC3 age scale (associated with a $\sim 2-3$ ka uncertainty) is further supported by an alternative orbital dating of the Dome F ice core producing a $\sim 2$ ka earlier onset of the LIG (Kawamura et al., 2007). 

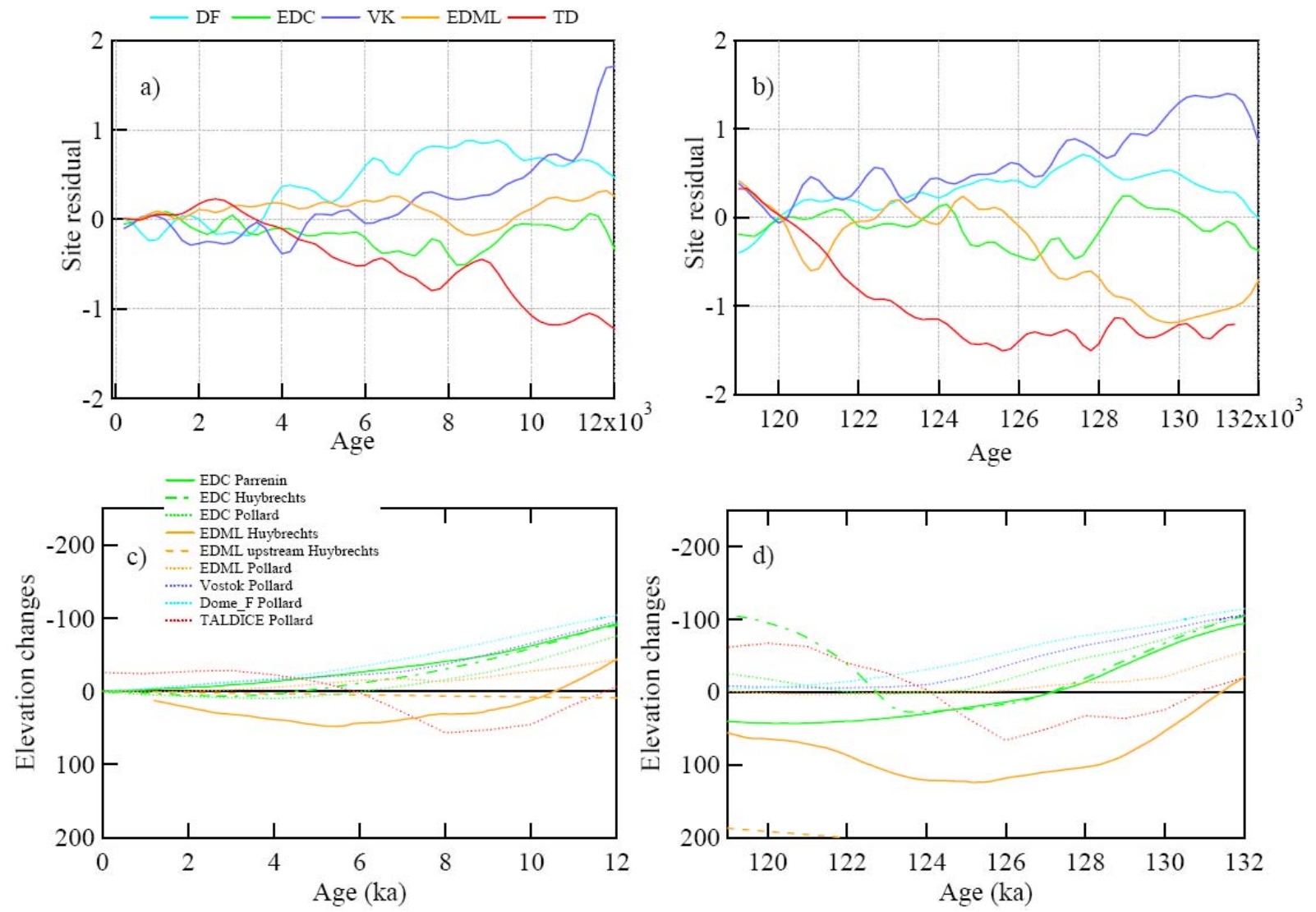

Fig. 7. (a) Current interglacial and (b) last interglacial $\delta^{18} \mathrm{O}$ residuals between each record and the first $\mathrm{PC}$ of the five records (PC1 from Fig. 5), expressed in \%o. The colour code is the same as in Fig. 2. 200 year data have been smoothed with a 3 point binomial filter and centred to have zero values respectively at 0 and $120 \mathrm{kyr}$. (c) and (d) anomalies of elevation changes simulated at EDML (orange), EDC (green), Vostok (blue) and Dome F (light blue) by Huybrechts et al. (2007) (long dashed line), Parrenin et al. (2007b) (solid line) and Pollard and DeConto (2009) (dotted line). Anomalies have been calculated with respect to the present day elevation (also displayed with the zero horizontal dashed black line). For EDML, the elevation change due to the geographical shift in surface ice origin (Huybrechts et al., 2007) ("upstream" dashed orange curve) is also displayed. The sizes of the left (Holocene) and right (last interglacial) panels have been adjusted to be proportional to the durations which are displayed.

\subsection{Local residuals}

In order to characterize the specificities of each ice core site, we have extracted the residual between each ice core record and the first principal component of the 5 records (Fig. 7, upper panels). For the Holocene, the EDML ice core exhibits a small positive anomaly during the early and secondary optima (decreasing towards the present) and a negative anomaly around $8 \mathrm{kyr}$; they all remain lower than $0.5 \%$. EDC shows no significant anomaly during the early Holocene optimum, a negative anomaly around $8 \mathrm{kyr}$, followed by an increasing trend towards the present; the anomalies also remain small (lower than 0.5\%o). By contrast, two sites have a tendency to display positive anomalies during the period 12 5 kyr: Vostok and DF. For Vostok, the anomaly peaks during the early Holocene (reaching 1.5\%o) and subsequently decreases. For DF, the anomaly is rather stable (almost $1 \%$ ) until $6 \mathrm{kyr}$, followed by a decrease. Finally, TALDICE exhibits a generally negative anomaly, maximum $(\sim 1 \%$ ) during the early Holocene optimum, which progressively declines until around $4 \mathrm{kyr}$. The EDML and EDC records are clearly those with minimum deviation from PC1 (from the sum of the squared residuals).

For the last interglacial, the same features are observed; note that upstream negative $\delta^{18} \mathrm{O}$ effects reaching about $1 \% o$ are expected for both Vostok and EDML (see Fig. 4b arrows). Again, (upstream corrected) EDML and Dome C show smaller deviations from the average than each of the other records. Again, Vostok and DF exhibit a positive residual (1 to $1.5 \%$ ), and TALDICE a negative residual (up to $1.5 \%$ ), particularly marked at the beginning of the Antarctic warm period (132 to $124 \mathrm{kyr}$ ).

From present day spatial gradients (Sect. 4$), \delta^{18} \mathrm{O}$ anomalies may be translated into elevation anomalies with a slope of $1 \%$ o per $100 \mathrm{~m}$ (see previous section). The site residuals can be compared with the local elevation changes as derived 
from 1-D (Parrenin et al., 2007b) or 3-D ice flow models (Huybrechts et al., 2007; Pollard and DeConto, 2009) (Fig. 7, lower panel). The latter model produces very small elevation anomalies during the late Holocene, positive elevation anomalies (reaching at most a few tens of $\mathrm{m}$ ) during the early Holocene (by decreasing magnitudes, for DF, Vostok, EDC and EDML) and a negative anomaly for TALDICE. The patterns of elevation changes modelled for the last interglacial appear comparable to those of the Holocene, with comparable magnitude; this may result from the simple marine record-based forcing of the Pollard and DeConto (2009) ice sheet model, which does not account for the changes in accumulation between the two periods as derived from the ice core data. We note that this model suggests a midinterglacial change in anomaly at TALDICE (at $6 \mathrm{kyr}$ and $124 \mathrm{kyr}$ ), which seems to occur later in the TALDICE residual. Finally, no modelling result can account for the observed EDML anomaly at the beginning of the last interglacial, suggesting spurious ice flow features close to EDML bedrock not accounted for by the current ice flow simulations, a feature previously noted by Stenni et al. (2010b).

The general features of the ice flow calculations support the view that multi-millennial local residuals may embed a small but significant local elevation signal, and that the ice flow calculations may underestimate past changes in elevation, especially during the last interglacial in some areas (e.g. TALDICE, Vostok, EDML). This points to a cautious interpretation of local isotopic differences only in terms of various isotope-temperature gradients. While the triplet (elevation, temperature, isotope-temperature slope) can be estimated in Greenland (Vinther et al., 2009), because both stable isotope and borehole temperature records are available as well as peripheral dome records with minimum elevation changes, the problem cannot be easily solved in Antarctica due to the current lack of independent constraints on past temperature and/or elevation changes.

\section{Conclusion and perspectives}

We have reviewed the modern glaciological and climatological contexts of these six East Antarctic sites. Meteorological observations, atmospheric analyses, back-trajectory and atmospheric modelling point to site-specific properties in terms of precipitation intermittency and moisture sources, but to coherent central East Antarctic Plateau variations in annual mean surface air temperature. We find very strong precipitation intermittency biasing effects across Antarctica; this implies that the "isotopic thermometer" is probably sensitive to climatic changes affecting precipitation intermittency. The difference in air mass trajectories and moisture sources for adjacent sites such as TALDICE and Taylor Dome is particularly intriguing. Further work to confirm this finding, for instance using moisture tagging in regional atmospheric circulation models, would be of considerable interest. Ice sheet dynamics are expected to have different responses at inland sites, where changes in local elevation appear to be mostly driven by accumulation history, and at coastal locations, where ice flow response is important.

The comparison of the available ice core oxygen 18 records depicts a strong homogeneity in East Antarctica during the present and last interglacial, which is likely due to a homogeneity of past temperature changes in the central East Antarctic Plateau. "Coastal" sites such as TD and TALDICE exhibit different characteristics. Both interglacials are marked by strong early and mid-period maxima. Within the EDC3 age scale, different phase lags are observed with respect to precession and obliquity maxima: the links between the East Antarctic signal and the orbital context remain elusive.

An analysis of the site-specific residuals highlights systematic differences, such as larger magnitudes of changes at Dome F than at EDC. Inter-site differences may arise because of differences in precipitation intermittency and covariance with temperature, resulting in different temporal isotope-temperature slopes (Sime et al., 2008). It can also be affected by changes in moisture origin as indicated by temperature inversion taking into account deuterium excess. Finally, small changes in elevation $(<200 \mathrm{~m})$ would be sufficient to account for the site-specific residuals. This possible importance of glaciological effects will need to be further investigated. Ice core data should be combined with ice sheet models to better estimate changes in ice volume of the East Antarctic ice sheet during past interglacials.

Although detailed inspection of the different "warm" periods reveals a complex picture, with non-constant ratios between sites, considerable similarities exist between the intersite geographical pattern of isotopic change during the Early Holocene and the last interglacial. A network of high spatial resolution ice core records is needed to document regional characteristics. Future work might investigate the differences between sites at shorter time scales, using improved age scale synchronization. Regional differences could also be tracked using an integrated perspective combining ice core stable isotope and aerosol records with marine sediment records, a target of the ESF HOLOCLIP initiative (http://www.holoclip.org/).

Further modelling investigations would be useful to better understand the causes of temporal and regional changes in the isotope-temperature relationships. Our analysis of inter-site differences, both during the instrumental period and between ice core records, suggests that very high spatial resolution atmospheric modelling is needed. Further work exploring and comparing the impacts on Antarctic isotope-temperature relationships of various forcings, such as changes in atmospheric greenhouse gas concentrations, orbital forcing, freshwater perturbations and changes in Antarctic ice sheet topography would be of high interest. Our preliminary comparison of site temperature reconstructions, taking into account deuterium excess constraints, suggests 
that changes in moisture origin may be at play, especially for Dome F and Vostok. Documenting deuterium excess and oxygen 17 excess along interglacials is therefore needed, both in terms of observations and isotopic general circulation model diagnoses.

The quantification of past regional temperature changes is likely affected by changes in precipitation intermittency and perhaps by changes in moisture sources. We note that the ice core records do not offer any direct means of quantifying the biases linked with precipitation intermittency. However, independent observational constraints of temperature and accumulation rate during interglacial periods could be obtained from $\delta^{15} \mathrm{~N}$ in the air trapped in Antarctic ice cores. Indeed, this parameter should give a faithful indication of the firn depth during interglacial periods when convective zones at the surface of the firn are negligible (Landais et al., 2006; Dreyfus et al., 2010). Firnification models forced by temperature and accumulation rate were shown to be reliable during this period (Landais et al., 2006). Hence, the combination of firnification models and $\delta^{15} \mathrm{~N}$ measurements may be a powerful tool to constraint past changes in temperature and accumulation rate, with added value for inverse dating methods (Parrenin et al., 2007a). However, in the meantime, we will likely remain dependent on atmospheric circulation modelling to help us explain the temporal and geographical patterns of isotopic change across multiple Antarctic ice cores.

A priority of the International Partnership for Ice Core Science (IPICS, http://www.pages-igbp.org/ipics/) is to improve the spatial coverage of Antarctic ice core records, in order to improve the documentation of regional climate variability. In addition to homogeneous temperature changes on the central East Antarctic Plateau, our comparison highlights two abrupt decreases in the isotopic values at the two most coastal TALDICE and EDML sites, around $118.5 \mathrm{kyr}$. These changes could be linked with regional changes in sea ice extent. Documenting the last interglacial in West Antarctic ice cores would complement our analysis, in an area where local elevation effects are expected to be particularly strong (Siddall et al., 2011).

Acknowledgements. We thank Gaël Durand for constructive discussions. H. S. acknowledges funding by the Norwegian Research Council in the framework of the project WaterSIP. This work is a contribution to EPICA, a joint European Science Foundation/European Commission scientific programme, funded by the EU (EPICA-MIS) and by national contributions from Belgium, Denmark, France, Germany, Italy, The Netherlands, Norway, Sweden, Switzerland, and the UK. The main logistic support was provided by IPEV and PNRA (at Dome C) and AWI (at Dronning Maud Land). The Talos Dome Ice core Project (TALDICE), a joint European programme, is funded by national contributions from Italy, France, Germany, Switzerland and the United Kingdom. Primary logistical support was provided by PNRA at Talos Dome. The inter-site comparison of past interglacials was supported by the ANR DOME A project (ANR-O7-BLAN-0125) and the analysis of modern climatic backgrounds by ANR VANISH. The research leading to these results has received funding from the European Union's Seventh Framework programme (FP7/2007-2013) under grant agreement 243908, "Past4Future. Climate change - Learning from the past climate", and is also a contribution to the ESF HOLOCLIP project. The HOLOCLIP Project, a joint research project of the European Science Foundation PolarCLIMATE programme, is funded by national contributions from Italy, France, Germany, Spain, Netherlands, Belgium and the United Kingdom. This is EPICA publication 274, TALDICE publication 12, Past4Future publication 5, HOLOCLIP publication 2 and LSCE publication 4488 .

Edited by: V. Rath

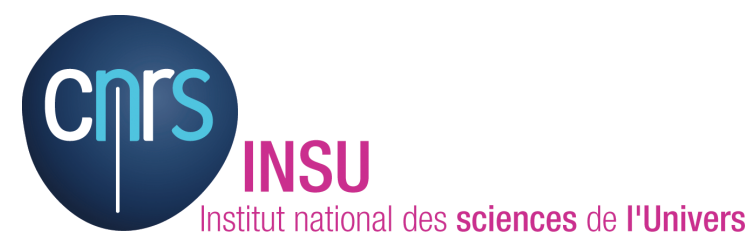

The publication of this article is financed by CNRS-INSU.

\section{References}

Bintanja, R., van de Wal, R., and Oerlemans, J.: Modelled atmospheric temperatures and global sea levels over the past million years, Nature, 437, 125-128, 2005.

Birnbaum, G., Brauner, R., and Ries, H.: Synoptic situations causing high precipitation rates on the Antarctic plateau: observations from Kohnen Station, DML, Antarct. Sci., 18, 279-288, 2006.

Brook, E. J., White, J. W. C., Schilla, A. S. M., Bender, M. L., Barnett, B., Severinghaus, J. P., Taylor, K. C., Alley, R. B., and Steig, E. J.: Timing of millenial-scale climate change at Siple Dome, West Antarctica, during the last glacial period, Quarternary Sci. Rev., 24, 1333-1343, 2005.

Buiron, D., Chappellaz, J., Stenni, B., Frezzotti, M., Baumgartner, M., Capron, E., Landais, A., Lemieux-Dudon, B., MassonDelmotte, V., Montagnat, M., Parrenin, F., and Schilt, A.: TALDICE-1 age scale of the Talos Dome deep ice core, East Antarctica, Clim. Past, 7, 1-16, doi:10.5194/cp-7-1-2011, 2011.

Capron, E., Landais, A., Chappellaz, J., Schilt, A., Buiron, D., Dahl-Jensen, D., Johnsen, S. J., Jouzel, J., Lemieux-Dudon, B., Loulergue, L., Leuenberger, M., Masson-Delmotte, V., Meyer, H., Oerter, H., and Stenni, B.: Millennial and sub-millennial scale climatic variations recorded in polar ice cores over the last glacial period, Clim. Past, 6, 345-365, doi:10.5194/cp-6-3452010, 2010.

Cuffey, K. M. and Vimeux, F.: Covariation of carbon dioxyde and temperature from the Vostok ice core after deuterium-excess correction, Nature 421, 523-527, 2001.

Dansgaard, W.: Stable isotopes in precipitation, Tellus, 16, 436468, 1964.

Debret, M., Sebag, D., Crosta, X., Massei, N., Petit, J. R., Chapron, E., and Bout-Roumazeilles, V.: Evidence from wavelet analysis for a mid-Holocene transition in global climate forcing, Quaternary Sci. Rev., 28, 25-26, 2009. 
Delaygue, G., Jouzel, J., Masson, V., Koster, R. D., and Bard, E.: Validity of the isotopic thermometer in central Antarctica; limited impact of glacial precipitation seasonality and moisture origin, Geophys. Res. Lett., 27, 2677-2680, 2000a.

Delaygue, G., Masson, V., Jouzel, J., and Koster, R. D.: The origin of Antarctic precipitation: a modelling approach, Tellus B, 52, 19-36, 2000b.

Divine, D., Isaksson, E., Kaczmarska, M., Goldliebsen, F., Oerter, H., Schlosser, E., Johnsen, S. J., van den Broecke, M., and Van de Wal, R.: Tropical Pacific-high latitude south Atlantic teleconnections as seen in $\delta^{18} \mathrm{O}$ variability in Antarctic coastal ice cores, J. Geophys. Res., 114, D11112, doi:10.1029/2008JD010475, 2009.

Dreyfus, G., Jouzel, J., Bender, M., Landais, A., Masson-Delmotte, V., and Leuenberger, M.: Firn processes and $\delta^{15} \mathrm{~N}$ : potential for a gas-phase climate proxy, Quarternary Sci. Rev., 29, 28-42, 2010.

Dunbar, N. W., McIntosh, W. C., and Esser, R. P.: Physical setting and tephrochronology of the summit caldera ice record at Mount Moulton, West Antarctica, GSA Bulletin, 120, 796-812, 2008.

Ekaykin, A. A.: Meteorological regime of central Antarctic and its role in the isotopic composition of snow thickness, $\mathrm{PhD}$ thesis, Sciences of Earth and Universe, Université Joseph Fourier, Grenoble, Grenoble, 120 pp., 2003.

Ekaykin, A. A., Lipenkov, V. Y., Kuzmina, I., Petit, J. R., MassonDelmotte, V., and Johnsen, S. J.: The changes in isotope composition and accumulation of snow at Vostok station, East Antarctica, over the past 200 years, Ann. Glaciol., 39, 569-575, 2004.

Ekaykin, A. A., Lipenkov, V. Y., Popov, S. V., and Shibaev, Y. A.: Glaciological and geophysical investigations of Antarctic ice sheet along the ice flow line passing through Vostok Station, SCAR Open Science Conference, Buenos Aires, 2010.

Enomoto, H., Motoyama, H., Shiraiwa, T., Saito, T., Kameda, T., Furukawa, T., Takahashi, S., Kodama, Y., and Watanabe, O.: Winter warming over Dome Fuji, East Antarctica, and semiannual oscillation in the atmospheric circulation, J. Geophys. Res., 103, 101-123, 1998.

EPICA-community-members: Eight glacial cycles from an Antarctic ice core, Nature, 429, 623-628, 2004.

EPICA-community-members: One-to-one coupling of glacial climate variability in Greenland and Antarctica, Nature, 444, 195198, 2006.

Fogt, R. L. and Bromwich, D.: Decadal variability of the ENSO teleconnection to the high latitude South Pacific governed by coupling with the Southern Annular Mode, J. Climte, 19, 979997, 2006.

Frezzotti, M., Pourchet, M., Flora, O., Gandolfi, S., Gay, M., Urbini, S., Vincent, C., Becagli, S., Gragnani, R., Proposito, M., Severi, M., Traversi, R., Udisti, R., and Fily, M.: New estimations of precipitation and surface sublimation in East Antarctica from snow accumulation measurements, Clim. Dynam., 23, 803813, 2004.

Fujita, K. and Abe, O.: Stable isotopes in daily precipitation at Dome Fuji, East Antarctica, Geophys. Res. Letters, 33, L18503, doi:18510.11029/12006GL026936, 2006.

Gallée, H. and Gorodetskaya, I.: Validation of a limited area model over Dome C, Antarctic Plateau, during winter, Clim. Dynam., 34, 61-72, 2010.

Genthon, C. and Cosme, E.: Intermittent signature of ENSO in west Antarctic precipitation, Geophys. Res. Lett., 30, 2081, doi:10.1029/2003GL018280, 2003.
Grootes, P. M., Steig, E. J., Stuiver, M., Waddington, E. D., and Morse, D. L.: The Taylor Dome Antarctic ${ }^{18} \mathrm{O}$ record and globally synchronous changes in climate, Quaternary Res., 56, 289298, 2001.

Hansen, J., Sato, M., Kharecha, P., Beerling, D., Berner, R., Masson-Delmotte, V., Pagani, M., Raymo, M. E., Royer, D. L., and Zachos, J. C.: Target atmospheric $\mathrm{CO}_{2}$ : where should humanity aim?, Open Atmos. Sci., 2, 217-231, 2008.

Hirasawa, N., Nakamura, H., and Yamanouchi, T.: Abrupt changes in meteorological conditions observed at an inland Antarctic station in association with wintertime blocking, Geophys. Res. Lett., 27, 1911-1914, 2000.

Holden, P. B., Edwards, N. R., Wolff, E. W., Lang, N. J., Singarayer, J. S., Valdes, P. J., and Stocker, T. F.: Interhemispheric coupling, the West Antarctic Ice Sheet and warm Antarctic interglacials, Clim. Past, 6, 431-443, doi:10.5194/cp-6-431-2010, 2010.

Huybers, P.: Antarctica's orbital beat, Science, 325, 1085-1086, 2009.

Huybers, P. and Denton, G. H.: Antarctic temperature at orbital timescales controlled by local summer duration, Nat. Geosci., 1, 787-792, 2008.

Huybrechts, P., Rybak, O., Pattyn, F., Ruth, U., and Steinhage, D.: Ice thinning, upstream advection, and non-climatic biases for the upper $89 \%$ of the EDML ice core from a nested model of the Antarctic ice sheet, Clim. Past, 3, 577-589, doi:10.5194/cp-3577-2007, 2007.

IPCC: Climate Change 2007 - The Physical Science Basis, Fourth Assessment Report, Cambridge University Press, Cambridge, 1009 pp., 2007.

Jouzel, J., Barkov, N. I., Barnola, J. M., Bender, M., Chappellaz, J., Genthon, C., Kotlyakov, V. M., Lipenkov, V., Lorius, C. R. P. J., Raynaud, D., Raisbeck, G., Ritz, C., Sowers, T., Stievenard, M., Yiou, F., and Yiou, P.: Extending the Vostok ice-core record of palaeoclimate to the penultimate glacial period, Nature, 364, 407-411, 1993.

Jouzel, J., Masson-Delmotte, V., Cattani, O., Falourd, S., Stievenard, M., Stenni, B., Longinelli, A., Johnsen, S., Steffenssen, J. P., Petit, J.-R., Schwander, J., Souchez, R., and Barkov, N. I.: A new $27 \mathrm{Kyr}$ high resolution East Antarctic climate record, Geophys. Res. Lett., in press, 2001.

Jouzel, J., Vimeux, F., Caillon, N., Delaygue, G., Hoffmann, G., Masson-Delmotte, V., and Parrenin, F.: Magnitude of the isotope-temperature scaling for interpretation of central Antarctic ice cores, J. Geophys. Res., 108, 1029-1046, 2003.

Jouzel, J., Masson-Delmotte, V., Cattani, O., Dreyfus, G., Falourd, S., Hoffmann, G., Minster, B., Nouet, J., Barnola, J. M., Chappellaz, J., Fischer, H., Gallet, J. C., Johnsen, S., Leuenberger, M., Loulergue, L., Luethi, D., Oerter, H., Parrenin, F., Raisbeck, G., Raynaud, D., Schilt, A., Schwander, J., Selmo, E., Souchez, R., Spahni, R., Stauffer, B., Steffensen, J. P., Stenni, B. S., Tison, J. L., Werner, M., and Wolff, E.: Orbital and millenial Antarctic climate variability over the past 800,000 years, Science, 317 , 793-796, 2007.

Kawamura, K., Parrenin, F., Lisiecki, L., Uemura, R., Vimeux, F., Severinghaus, J. P., Hutterli, M. A., Nakazawa, T., Aoki, S., Jouzel, J., Raymo, M. E., Matsumoto, K., Nakata, H., Motoyama, H., Fujita, S., Goto-Azuma, K., Fujii, Y., and Watanabe, O.: Northern Hemisphere forcing of climatic cycles in Antarctica over the past 360,000 years, Nature, 448, 912-915, 2007. 
Krinner, G. and Werner, M.: Impact of precipitation seasonality changes on isotopic signals in polar ice cores, Earth Planet. Sc. Lett., 216, 525-538, 2003.

Krinner, G., Genthon, C., and Jouzel, J.: GCM analysis of local influences on ice core $\delta$ signals, Geophys. Res. Lett., 24, 28252828, 1997.

Krinner, G., Magand, O., Simmonds, I., Genthon, C., and Dufresne, J. L.: Simulated Antarctic precipitation and surface mass balance at the end of the twentieth century, Clim. Dynam., 28, 215-230, 2007.

Kwok, R. and Comiso, J. C.: Spatial patterns of variability in Antarctic surface temperature: connections to the Southern Hemisphere Annular mode and the Southern Oscillation, Geophys. Res. Lett., 29, 1705, doi:10.1029/2002GL015415, 2002.

Landais, A., Masson-Delmotte, V., Jouzel, J., Raynaud, D., Johnsen, S., Huber, C., Leuenberger, M., Schwander, J., and Minster, B.: The glacial inception recorded in the NorthGRIP Greenland ice core: information from air isotopic measurements, Clim. Dynam., 26, 273-284, 2006.

Landais, A., Barnola, J. M., Kawamura, K., Caillon, N., Delmotte, M., Ommen, T. V., Dreyfus, G., Jouzel, J., Masson-Delmotte, V., Minster, B., Freitag, J., Leuenberger, M., Schwander, J., Huber, C., Etheridge, D., and Morgan, V.: Firn-air $\delta^{15} \mathrm{~N}$ in modern polar sites and glacial-interglacial ice : a model-data mismatch during glacial periods in Antarctica, Quaternary Sci. Rev., 25, 49-62, 2006.

Laskar, J., Joutel, F., and Boudin, F.: Orbital, precessional, and insolation quantities for the Earth from $-20 \mathrm{Myr}$ to $+10 \mathrm{Myr}$, Astron. Astrophys., 270, 522-533, 1993.

Lemieux-Dudon, B., Barnola, J. M., Narcisi, B., Parrenin, F., Petit, J. R., Ritz, C., Svensson, A., and Waelbroeck, C.: Consistent dating for Antarctica and Greenland ice cores, Quaternary Sci. Rev., 29, 8-20, 2010.

Loulergue, L., Schilt, A., Spahni, R., Masson-Delmotte, V., Blunier, T., Lemieux, B., Barnola, J. M., Raynaud, D., Stocker, T., and Chappelaz, J.: Orbital and millenial-scale features of atmospheric $\mathrm{CH}_{4}$ over the last 800000 years, Nature, 453, 383-386, 2008.

Marino, F., Castellano, E., Nava, S., Chiari, M., Ruth, U., Wegner, A., Lucarelli, F., Udisti, R., Delmonte, B., and Maggi, V.: Coherent composition of glacial dust on opposite sides of the Earth Antarctic Plateau inferred from the deep EPICA ice cores, Geophys. Res. Lett., 36, L23703, doi:10.1029/2009GL040732, 2009.

Marshall, G. J.: Trends in the southern annular mode from observations and reanalyses, J. Climate, 16, 4134-4143, 2003.

Marshall, G. J.: Half-century seasonal relationship between the Southern Annular Mode and Antarctic temperatures, Int. J. Climatol., 27, 373-383, 2007.

Marshall, G. J.: On the annual and semi-annual cycles of precipitation accross Antarctica, Int. J. Climatol., 29, 2298-2308, 2009.

Massom, R. A., Pook, M. J., Comiso, J. C., Adams, N., Turner, J., Lachlan-Cope, T. A., and Gibson, T. T.: Precipitation over the interior East Antarctic ice sheet related to midlatitude blocking activity, J. Climate, 17, 1914-1928, 2004.

Masson, V., Vimeux, F., Jouzel, J., Morgan, V., Delmotte, M., Ciais, P., Hammer, C., Johnsen, S., Lipenkov, V. Y., Mosley-Thompson, E., Petit, J.-R., Steig, E., Stievenard, M., and Vaikmae, R.: Holocene climate variability in Antarctica based on 11 ice cores isotopic records, Quaternary Res., 54, 348-358, 2000.
Masson-Delmotte, V., Stenni, B., and Jouzel, J.: Common millennial-scale variability of Antarctic and Southern Ocean temperatures during the past 5000 years reconstructed from the EPICA Dome C ice core, Holocene, 14(2), 145-151, 2004.

Masson-Delmotte, V., Dreyfus, G., Braconnot, P., Johnsen, S., Jouzel, J., Kageyama, M., Landais, A., Loutre, M.-F., Nouet, J., Parrenin, F., Raynaud, D., Stenni, B., and Tuenter, E.: Past temperature reconstructions from deep ice cores: relevance for future climate change, Clim. Past, 2, 145-165, doi:10.5194/cp2-145-2006, 2006a.

Masson-Delmotte, V., Kageyama, M., Braconnot, P., Charbit, S., Krinner, G., Ritz, C., Guilyardi, E., Jouzel, J., Abe-Ouchi, A., Crucifix, M., Gladstone, R. M., Hewitt, C. D., Kitoh, A., Legrande, A., Marti, O., Merkel, U., Motoi, T., Ohgaito, R., Otto-Bliesner, B., Peltier, R. W., Ross, I., Valdes, P., Vettoretti, G., Weber, S. L., and Wolk, F.: Past and future polar amplification of climate change: climate model intercomparisons and ice-core constraints, Clim. Dynam., 27, 437-440, 2006b.

Masson-Delmotte, V., Hou, S., Ekaykin, A., Jouzel, J., Aristarain, A., Bernardo, R. T., Bromwhich, D., Cattani, O., Delmotte, M., Falourd, S., Frezzotti, M., Gallée, H., Genoni, L., Isaksson, E., Landais, A., Helsen, M., Hoffmann, G., Lopez, J., Morgan, V., Motoyama, H., Noone, D., Oerter, H., Petit, J. R., Royer, A., Uemura, R., Schmidt, G. A., Schlosser, E., Simões, J. C., Steig, E., Stenni, B., Stievenard, M., v. d. Broeke, M., v. d. Wal, R., v. d. Berg, W.-J., Vimeux, F., and White, J. W. C.: A review of Antarctic surface snow isotopic composition : observations, atmospheric circulation and isotopic modelling, J. Climate, 21, 3359-3387, 2008.

Masson-Delmotte, V., Stenni, B., Blunier, T., Cattani, O., Chappellaz, J., Cheng, H., Dreyfus, G., Edwards, R. L., Falourd, S., Govin, A., Kawamura, K., Johnsen, S. J., Jouzel, J., Landais, A., Lemieux-Dudon, B., Lourantou, A., Marshall, G. J., Minster, B., Mudelsee, M., Pol, K., Rothlisberger, R., Selmo, E., and Waelbroeck, C.: An abrupt change of Antarctic moisture origin at the end of termination II, P. Natl. Acad. Sci., 107, 12091-12094, doi:10.1073/pnas.0914536107, 2010a.

Masson-Delmotte, V., Stenni, B., Pol, K., Braconnot, P., Cattani, O., Falourd, S., Kageyama, M., Jouzel, J., Landais, A., Minster, B., Krinner, G., Johnsen, S., Röthlisberger, R., Chappellaz, J., Hansen, J., Mikolajewicz, U., and Otto-Bliesner, B.: EPICA Dome $\mathrm{C}$ record of glacial and interglacial intensities, Quaternary Sci. Rev., 29, 113-128, 2010 b.

Merlivat, L. and Jouzel, J.: Global climatic interpretation of the deuterium-oxygen 18 relationship for precipitation, J. Geophys. Res., 84, 5029-5033, 1979.

Miles, G. M., Marshall, G. J., McConnell, J. R., and Aristarain, A.: Recent accumulation variability and change on the Antarctic Peninsula from the ERA40 reanalysis, Int. J. Climatol., 28, 1409-1422, 2008.

Morse, D. L., Waddington, E. D., and Steig, E. J.: Ice age storm trajectories inferred from radar stratigraphy at Taylor Dome, Antarctica, Geophys. Res. Lett., 25, 3383-3386, 1998.

Morse, D. L., Waddington, E. D., and Rasmussen, L. A.: Ice deformation in the vicinity of the ice-core site at Taylor Dome, Antarctica, and a derived accumulation rate history, J. Glaciol., 53, 449-460, 2007. 
Mulvaney, R., Röthlisberger, R., Wolff, E. W., Sommer, S., Schwander, J., Hutterli, M. A., and Jouzel, J.: The transition from the last glacial period in inland and near-coastal Antarctica, Geophys. Res. Lett., 27, 2673-2676, 2000.

Noone, D. and Simmonds, I.: Implications for interpretations of ice-core isotope data from analysis of modelled Antarctic precipitation, Ann. Glaciol., 27, 398-402, 1998.

NorthGRIP-community-members: High resolution climate record of the Northern Hemisphere reaching into last interglacial period, Nature, 431, 147-151, 2004.

Otto-Bliesner, B. L., Marshall, S. J., Overpeck, J. T., Miller, G. H., Hu, A., and members, C. 1. i. p.: Simulating Arctic climate warmth and icefield retreat in the last interglaciation, Science, 311, 1751-1753, 2006.

Overpeck, J. T., Otto-Bliesner, B. L., Miller, G. H., Muhs, D. R., Alley, R. B., and Kiehl, J. T.: Paleoclimatic evidence for future ice-sheet instability and rapid sea-level rise, Sci. China, 311, 1747-1750, 2006.

Paillard, D., Labeyrie, L., and Yiou, P.: Macintosh program performs time-series analysis, EOS trans, AGU, 77, 379, 1996.

Parrenin, F., Jouzel, J., Waelbroeck, C., Ritz, C., and Barnola, J.-M.: Dating of the Vostok ice core by an inverse method, J. Geophys. Res., 106, 31837-31851, 2001.

Parrenin, F., Rémy, F., Ritz, C., Siegert, M. J., and Jouzel, J.: New modellling of the Vostok ice flow line and implication for the glaciological chronology of the Vostok ice core, J. Geophys. Res., 109, D20102, doi:20110.21029/22004JD004561, 2004.

Parrenin, F., Barnola, J.-M., Beer, J., Blunier, T., Castellano, E., Chappellaz, J., Dreyfus, G., Fischer, H., Fujita, S., Jouzel, J., Kawamura, K., Lemieux-Dudon, B., Loulergue, L., MassonDelmotte, V., Narcisi, B., Petit, J.-R., Raisbeck, G., Raynaud, D., Ruth, U., Schwander, J., Severi, M., Spahni, R., Steffensen, J. P., Svensson, A., Udisti, R., Waelbroeck, C., and Wolff, E.: The EDC3 chronology for the EPICA Dome C ice core, Clim. Past, 3, 485-497, doi:10.5194/cp-3-485-2007, 2007a.

Parrenin, F., Dreyfus, G., Durand, G., Fujita, S., Gagliardini, O., Gillet, F., Jouzel, J., Kawamura, K., Lhomme, N., MassonDelmotte, V., Ritz, C., Schwander, J., Shoji, H., Uemura, R., Watanabe, O., and Yoshida, N.: 1-D-ice flow modelling at EPICA Dome C and Dome Fuji, East Antarctica, Clim. Past, 3, 243-259, doi:10.5194/cp-3-243-2007, 2007b.

Petit, J. R. and Delmonte, B.: A model for large glacial-interglacial climate-induced changes in dust and sea salt concentrations in deep ice cores (central Antarctica): palaeoclimatic implications and prospects for refining ice core chronologies, Tellus B, 61, 768-790, 2009.

Petit, J. R., Jouzel, J., Raynaud, D., Barkov, N. I., Barnola, J.-M., Basile, I., Bender, M., Chappellaz, J., Davis, J., Delaygue, G., Delmotte, M., Kotlyakov, V. M., Legrand, M., Lipenkov, V., Lorius, C., Pépin, L., Ritz, C., Saltzman, E., and Stiévenard, M.: Climate and Atmospheric History of the Past 420000 years from the Vostok Ice Core, Antarctica, Nature, 399, 429-436, 1999.

Pol, K., Masson-Delmotte, V., Johnsen, S., Bigler, M., Cattani, O., Durand, G., Falourd, S., Jouzel, J., Minster, B., Parrenin, F., Ritz, C., Steen-Larsen, H. C., and Stenni, B.: New MIS19 EPICA Dome $\mathrm{C}$ high resolution deuterium data: hints for a problematic preservation of climate variability in the "oldest ice", Earth Planet. Sc. Lett., 298, 95-103, 2011.
Pollard, D. and DeConto, R. M.: Modelling West Antarctic ice sheet growth and collapse through the past five million years, Nature, 458, 329-332, 2009.

Popp, T., Sowers, T., Dunbar, N. W., McIntosh, W. C., and White, J. W. C.: Radioisotopically dated climate record spanning the last interglacial in ice from Mount Moulton, West Antarctica, EOS Trans. Am. Geophys. Union, 85, 2004.

Powers, J. G., Monaghan, A. J., Cayette, A. M., Bromwich, D. H., Kuo, Y., and Manning, K. W.: Real-time mesocale modeling over Antarctica: the Antarctic Mesoscale Prediction System, B. Am. Meteorol. Soc., 84, 1522-1545, 2003.

Rasmussen, S. O., Andersen, K. K., Svensson, A. M., Steffensen, J. P., Vinther, B. M., Clausen, H. B., Siggaard-Andersen, M.L., Johnsen, S. J., Larsen, L. B., Dahl-Jensen, D., Bigler, M., Röthlisberger, R., Fischer, H., Goto-Azuma, K., Hansson, M. E., and Ruth, U.: A new Greenland ice core chronology for the last glacial termination, J. Geophys. Res., 111, D06102, doi:10.1029/2005JD006079, 2006.

Reijmer, H., van den Broeke, R., and Scheele, M. P.: Air parcel trajectories and snowfall related to five deep drilling locations in Antarctica based on the ERA-15 dataset, J. Climate, 15, 19571968, 2002.

Renssen, H., Goosse, H., Fichefet, T., Masson-Delmotte, V., and Koç, N.: The Holocene climate evolution in the high latitude Southern Hemisphere simulated by a coupled atmosphere sea ice ocean vegetation model, Holocene, 15, 951-964, 2004.

Renssen, H., Goosse, H., Crosta, X., and Roche, D. M.: Early Holocene Laurentide Ice Sheet deglaciation causes cooling in the high latitude Southern Hemisphere through oceanic teleconnection, Paleoceanography, 25, PA3204, doi:10.1029/2009PA001854, 2010.

Röthlisberger, R., Mudelsee, M., Bigler, M., de Angelis, M., Fischer, H., Hansson, M., Lambert, F., Masson-Delmotte, V., Sime, L., Udisti, R., and Wolff, E. W.: The Southern Hemisphere at glacial terminations: insights from the Dome $\mathrm{C}$ ice core, Clim. Past, 4, 345-356, doi:10.5194/cp-4-345-2008, 2008.

Ruth, U., Barnola, J.-M., Beer, J., Bigler, M., Blunier, T., Castellano, E., Fischer, H., Fundel, F., Huybrechts, P., Kaufmann, P., Kipfstuhl, S., Lambrecht, A., Morganti, A., Oerter, H., Parrenin, F., Rybak, O., Severi, M., Udisti, R., Wilhelms, F., and Wolff, E.: "EDML1": a chronology for the EPICA deep ice core from Dronning Maud Land, Antarctica, over the last 150000 years, Clim. Past, 3, 475-484, doi:10.5194/cp-3-475-2007, 2007.

Salamatin, A. N., Tsyganova, E. A., Popov, S. V., and Lipenkov, V. Y.: Ice flow line modeling in ice core data interpretation: Vostok Station (East Antarctica), in: Physics of Ice Core Records, edited by: Hondoh, T., Hokkaido Univ. Press, Sapporo, 167-194, 2009.

Scarchilli, C., Frezzotti, M., and Ruti, P.: Snow precipitation at four ice core sites in East Antarctica: provenance, seasonality and blocking factors, Clim. Dynam., doi:10.1007/s00382-010-09464, in press, 2010.

Schlosser, E., Duda, M. G., Powers, J. G., and Manning, K. H.: The precipitation regime of Dronning Maud Land, Antarctica, derived from AMPS (Antarctic Mesoscale Prediction System) Archive Data, J. Geophys. Res., 113, D14107, doi:10.1029/2008JD009968, 2008. 
Schlosser, E., Manning, K. W., Powers, J. G., Duda, M. G., Birnbaum, G., and Fujita, K.: Characteristics of high-precipitation events in Dronning Maud Land, Antarctica, J. Geophys. Res., 115, D14107, doi:10.1029/2009JD013410, 2010a.

Schlosser, E., Powers, J. G., Duda, M. G., Manning, K. W., Reijmer, C. H., and Van den Broecke, M.: An extreme precipitation event in Dronning Maud Land, Antarctica - a case study using AMPS (Antarctic Mesoscale Prediction System) archive data, Polar Res., 29, 330-344, 2010 b.

Schmidt, G. A., Legrande, A., and Hoffmann, G.: Water isotope expressions of intrinsic and forced variability in a coupled ocean-atmosphere model, J. Geophys. Res., 112, D10103, doi:10.1029/2006JD007781, 2007.

Severinghaus, J. P. and Brook, E.: Simultaneous tropical-Arctic abrupt climate change at the end of the last glacial period inferred from trapped air in polar ice, Science, 286, 930-934, 1999.

Shackleton, N. J., Sanchez-Goñi, M. F., Pailler, D., and Lancelot, Y.: Marine isotope substage 5e and the Eemian interglacial, Global Planet. Changes, 36, 151-155, 2003.

Siddall, M., Milne, G. A., and Masson-Delmotte, V.: Uncertainties in elevation changes and their impact on Antarctic temperature records since the end of the last glacial period, Earth Planet. Sc. Lett., in revision, 2011.

Siegenthaler, U., Stocker, T. F., Monnin, E., Lüthi, D., Schwander, J., Stauffer, B., Raynaud, D., Barnola, J.-M., Fischer, H., Masson-Delmotte, V., and Jouzel, J.: Stable carbon cycle-climate relationship during the last Pleistocene, Science, 310, 13131317, 2005.

Sime, L. C., Tindall, J. C., Wolff, E. W., Connolley, W. M., and Valdes, P. J.: Antarctic isotopic thermometer during a $\mathrm{CO}_{2}$ forced warming event, J. Geophys. Res., 113, D24119, doi:10.1029/2008jd010395, 2008.

Sime, L. C., Marshall, G. J., Mulvaney, R., and Thomas, E. R.: Interpreting temperature information from ice cores along the Antarctic Peninsula: ERA40 analysis, Geophys. Res. Lett., 36, L18801, doi:18810.11029/12009GL038982, 2009a.

Sime, L. C., Wolff, E. W., Oliver, K. I. C., and Tindall, J. C.: Evidence for warmer interglacials in East Antarctic ice cores, Nature, 462, 342-345, 2009b.

Sodemann, H. and Stohl, A.: Asymmetries in the moisture origin of Antarctic precipitation, Geophys. Res. Lett., 36, L22803, doi:10.1029/2009GL040242, 2009.

Sodemann, H., Schwierz, C., and Wernli, H.: Inter-annual variability of Greenland winter precipitation sources, Lagrangian moisture diagnostic and North Atlantic Oscillation influence, J. Geophys. Res., 113, D03107, doi:03110.01029/02007JD008503, 2008.

Steig, E., Brook, E. J., White, J. W. C., Sucher, C. M., Bender, M. L., Lehman, S. J., Morse, D. L., Waddigton, E. D., and Clow, G. D.: Synchronous climate changes in Antarctica and the North Atlantic, Science, 282, 92-95, 1998.

Steig, E. J., Grootes, P. M., and Stuiver, M.: Seasonal precipitation timing and ice core records, Science, 266, 1885-1886, 1994.

Stenni, B., Masson, V., Johnsen, S. J., Jouzel, J., Longinelli, A., Monnin, E., Rothlisberger, R., and Selmo, E.: An oceanic cold reversal during the last deglaciation, Science, 293, 2074-2077, 2001.
Stenni, B., Masson-Delmotte, V., Selmo, E., Oerter, H., Meyer, H., Rothlisberger, R., Jouzel, J., Cattani, O., Falourd, S., Fischer, H., Hoffmann, G., Iacumin, P., Johnsen, S. J., Minster, B., and Udisti, R.: The deuterium excess records of EPICA Dome $\mathrm{C}$ and Dronning Maud Land ice cores (East Antarctica), Quaternary Sci. Rev., 29, 146-159, doi:10.1016/j.quascirev.2009.10.009, 2010a.

Stenni, B., Masson-Delmotte, V., Selmo, E., Oerter, H., Meyer, H., Röthlisberger, R., Jouzel, J., Cattani, O., Falourd, S., Fischer, H., Hoffmann, G., Iacumin, P., Johnsen, S. J., Minster, B., and Udisti, R.: The deuterium excess records of EPICA Dome $\mathrm{C}$ and Dronning Maud Land ice cores (East Antarctica), Quaternary Sci. Rev., 29, 146-159, 2010b.

Stenni, B., Buiron, D., Frezzotti, M., Albani, S., Barbante, C., Bard, E., Barnola, J. M., Baroni, C., Baumgartner, S., Bonazza, M., Capron, E., Castellano, E., Chappellaz, J., Delmonte, B., Falourd, S., Genoni, L., Iacumin, P., Jouzel, J., Kipfsthul, J., Landais, A., Lemieux-Dudon, B., Maggi, V., Masson-Delmotte, V., Mazzola, C., Minster, B., Montagnat, M., Mulvaney, R., Narcisi, B., Oerter, H., Parrenin, F., Petit, J. R., Ritz, C., Scarchilli, C., Schilt, A., Schüpbach, E., Schwander, J., Selmo, E., Severi, M., Stocker, T., and Udisti, R.: The expression of the bipolar climate seesaw around Antarctica during the last deglaciation, Nat. Geosci., 4, 46-49, 2011.

Suzuki, K., Yamanouchi, T., and Motoyama, H.: Moisture transport to Syowa and Dome Fuji stations in Antarctica, J. Geophys. Res., 113, D24114, doi:10.1029/2008JD009794, 2008.

Timmermann, A., Timm, O., Stott, L., and Menviel, L.: The roles of $\mathrm{CO}_{2}$ and orbital forcing in driving southern hemispheric temperature variations during the last 21,000 years, J. Climate, 22, 1626-1640, 2009.

Udisti, R., Becagli, S., Castellano, E., Delmonte, B., Jouzel, J., Petit, J. R., Schwander, J., Stenni, B., and Wolff, E. W.: Stratigraphic correlations between the European Project for Ice Coring in Antarctica (EPICA) Dome $\mathrm{C}$ and Vostok ice cores showing the relative variations of snow accumulation over the past $45 \mathrm{kyr}$, J. Geophys. Res., 109, D08101, doi:10.1029/2003JD004180, 2004.

Uemura, R., Yoshida, N., Kurita, N., Nakawo, M., and Watanabe, O.: An observation-based method for reconstructing ocean surface changes using a 340,000 year deuterium excess record from the Dome Fuji ice core, Antarctica, Geophys. Res. Lett., 31, L13216, doi:10.1029/2004GL019954, 2004.

Uemura, R., Matsui, Y., Yoshimura, K., Motoyama, H., and Yoshida, N.: Evidence of deuterium excess in water vapor as an indicator of ocean surface conditions, J. Geophys. Res., 113, D19114, doi:10.1029/2008jd010209, 2008.

Urbini, S., Frezzotti, M., Gandolfi, S., Vincent, C., Scarchilli, C., Vittuari, L., and Fily, M.: Historical behaviour of Dome C and Talos Dome (East Antarctica) as investigated by snow accumulation and ice velocity measurements, Global Planet. Change, 60, 576-588, doi:10.1016/j.gloplacha.2007.08.002, 2008.

Vimeux, F., Masson, V., Jouzel, J., Stievenard, M., and Petit, J. R.: Glacial-interglacial changes in ocean surface conditions in the Southern Hemisphere, Nature, 398, 410-413, 1999.

Vimeux, F., Masson, V., Delaygue, G., Jouzel, J., Petit, J.-R., and Stievenard, M.: A 420,000 year deuterium excess record from East Antarctica : Information on past changes in the origin of precipitation at Vostok, J. Geophys. Res., 106, 31863-31873, 2001a. 
Vimeux, F., Masson, V., Jouzel, J., Petit, J. R., Steig, E. J., Stievenard, M., Vaikmae, R., and White, J. W. C.: Holocene hydrological cycle changes in the Southern Hemisphere documented in East Antarctic deuterium excess records, Clim. Dynam., 17, 503-513, 2001b.

Vimeux, F., Cuffey, K. M., and Jouzel, J.: New insights into Southern Hemisphere temperature changes from Vostok ice cores using deuterium excess correction over the last 420,000 years, Earth Planet. Sci. Lett., 203, 829-843, 2002.

Vinther, B. M., Clausen, H. B., Johnsen, S. J., Rasmussen, S. O., Andersen, K. K., Buchardt, S. L., Dahl-Jensen, D., Seierstad, I., Siggaard-Andersen, M.-L., Steffensen, J. P., Svensson, A., Olsen, J., and Heinemeier, J.: A synchronized dating of three Greenland ice cores throughout the Holocene, J. Geophys. Res., 111, D13102, doi:10.1029/2005JD006921, 2006.

Vinther, B. M., Buchardt, S. L., Clausen, H. B., Dahl-Jensen, D., Johnsen, S. J., Fischer, D. A., Koerner, R. M., Raynaud, D., Lipenkov, V., Andersen, K. K., Blunier, T., Rasmussen, S. O., Steffensen, J. P., and Svensson, A. M.: Holocene thinning of the Greenland ice sheet, Nature, 461, 385-388, 2009.
Watanabe, O., Jouzel, J., Johnsen, S., Parrenin, F., Shoji, H., and Yoshida, N.: Homogeneous climate variability across East Antarctica over the past three glacial cycles, Nature, 422, 509512, 2003.

Werner, M. and Heimann, M.: Modeling interannual variability of water isotopes in Greenland and Antarctica, J. Geophys. Res., 107, 1-13, 2002.

Werner, M., Heimann, M., and Hoffmann, G.: Isotopic composition and origin of polar precipitation in present and glacial climate simulations, Tellus B, 53, 53-71, 2001.

Wolff, E. W., Barbante, C., Becagli, S., Bigler, M., Boutron, C., Castellano, E., De Angelis, M., Federer, B., Fischer, H., Fundel, F., Hansson, M., Hutterli, M., Jonsell, U., Karlin, T., Kaufmann, P., Lambert, F., Littot, G., Mulvaney, R., Röthlisberger, R., Ruth, U., Severi, M., Siggaard-Andersen, M.-L., Sime, L., Steffensen, J. P., Stocker, T., Traversi, R., Twarloh, B., Udisti, R., Wagenbach, D., and Wegner, A.: Changes in environment over the last 800,000 years from chemical anlayses of the EPICA Dome C ice core, Quarternary Sci. Rev., 29, 285-295, 2010. 